\title{
Parallel introgression, not recurrent emergence, explains apparent elevational ecotypes of polyploid Himalayan snowtrout
}

\author{
Tyler K. Chafin ${ }^{1,2}$, Binod Regmi ${ }^{1,3}$, Marlis R. Douglas ${ }^{1}$, David R. Edds ${ }^{4}$, Karma Wangchuk ${ }^{1,5}$, \\ Sonam Dorji ${ }^{5}$, Pema Norbu ${ }^{5}$, Sangay Norbu ${ }^{5}$, Changlu Changlu ${ }^{5}$, Gopal Prasad $\mathrm{Khanal}^{5}$, Singye \\ Tshering ${ }^{5}$, and Michael E. Douglas ${ }^{1}$
}

${ }^{1}$ Department of Biological Sciences, University of Arkansas, Fayetteville, Arkansas USA 72701

${ }^{2}$ Department of Ecology and Evolutionary Biology, University of Colorado, Boulder USA 80309

${ }^{3}$ National Institute of Arthritis, Musculoskeletal \& Skin Diseases (NIAMS), National Institutes of Health, Bethesda, Maryland, Maryland USA 20892

${ }^{4}$ Department of Biological Sciences, Emporia State University, Emporia, Kansas USA 66801

${ }^{5}$ National Research and Development Centre for Riverine \& Lake Fisheries, Ministry of Agriculture \& Forests, Royal Government of Bhutan, Haa Bhutan

Keywords: Adaptation, ecotype, convergent evolution, parallel evolution, polyploidy, introgression

Disclosure statement: Authors have nothing to disclose. 
(200/200) The recurrence of similar evolutionary patterns within different habitats often reflects

2 parallel selective pressures acting upon either standing or independently occurring genetic variation to produce a convergence of phenotypes. This interpretation (i.e. parallel divergences

4 within adjacent streams) has been hypothesized for drainage-specific morphological 'ecotypes' observed in polyploid snowtrout (Cyprinidae: Schizothorax). However, parallel patterns of

6 differential introgression during secondary contact is a viable alternative hypothesis. Here, we utilized ddRADseq ( $N=35,319$ de-novo and $N=10,884$ transcriptome-aligned SNPs), as derived

8 from Nepali/Bhutanese samples ( $N=48$ each), to test these competing hypotheses. We first employed genome-wide allelic depths to derive appropriate ploidy models, then a Bayesian

10 approach to yield genotypes statistically consistent under the inferred expectations. Elevational 'ecotypes' were consistent in geometric-morphometric space, but with phylogenetic relationships

12 at the drainage-level, sustaining an hypothesis of independent emergence. However, partitioned analyses of phylogeny and admixture identified subsets of loci under selection that retained

14 genealogical concordance with morphology, suggesting instead that apparent patterns of morphological/phylogenetic discordance are driven by widespread genomic homogenization.

16 Here, admixture occurring in secondary contact effectively 'masks' previous isolation. Our results underscore two salient factors:1) Morphological adaptations are retained despite

18 hybridization; and 2) The degree of admixture varies across tributaries, presumably concomitant with underlying environmental or anthropogenic factors. 


\section{1. Introduction}

Selection for local environmental conditions can drive rapid evolution, and occasionally does so

24 within parallel systems [1]. This, in turn, can promote the emergence of unique ecotypes, or even novel species [2-4]. Adaptations to ecological gradients can also occur, especially in the absence

26 of geographic isolation, and are commonly attributed to selection acting upon existing variation [either ancestral/standing [5,6], or that acquired through hybridization [7-11]]. These represent

28 but two of several scenarios through which such patterns can be generated [12-14].

Divergent selection in response to ecological gradients can also facilitate speciation, even

30 when gene flow is ongoing [15-17]. A hallmark of this process is the formation of genomic 'islands of divergence,' with selection and its cumulative effects serving to counterbalance

32 homogenizing gene flow [18-22]. These so-called 'islands' may then expand via a hitchhiking mechanism, such that divergence is also initiated within linked genomic regions [23-26].

34 However, heterogeneous genomic divergence can also arise via entirely different processes, to include those wholly unrelated to speciation. This, in turn, introduces an analytical dilemma, in

36 that the signatures of one can either obfuscate or instead emulate that of the other [27-29].

The resulting emergence of parallel ecotypes is often manifested phylogenetically as

38 clusters within study sites or regions, rather than among eco-phenotypes [30]. However, an alternative is that ecological adaptations instead evolve via isolation followed by subsequent

40 dispersal, such that genomic loci are now juxtaposed across both distributions and genomes $[12,31,32]$. 'Genomic islands' as well as phylogenetic patterns are then generated similar to those

42 manifested by parallel divergence-with-gene-flow (per above). This can occur, for example, when introgression is constrained within localized genomic regions that underlie with adaptation

44 to an ecological gradient [33]. Genome-wide homogenization is the result, with ancestral 
branching patterns (e.g., those uniting ecotypes) now restricted to regions where permeability to

46 gene flow is reduced by selection and/or low recombination [34,35]. However, the singular origin of an adaptive allele spread selectively via localized introgression can also yield relatively

48 similar genomic patterns [36-38].

Together, this implicates four distinct scenarios that could generate genomic landscapes

50 compatible with those expected under parallel ecotype emergence. Yet only two of these necessitate divergence-with-gene-flow, e.g., with selection acting in a repetitive fashion on either

52 A) standing genetic variation or B) independent de novo mutations. In contrast, two alternative scenarios involve adaptive variability accumulated while in isolation, followed by secondary

54 gene flow among dispersing ecotypes. This then results in: C) selective filtering against a background of genomic homogenization; or D) the selective introgression of adaptive alleles into novel populations (figure 1). Thus, while all are effectively operating in 'parallel' (e.g., in separate river drainages or habitat patches), their relationship to the diversification process

58 differs substantially. This presents a challenge for the interpretation of such patterns, in that those superficially similar may in fact reflect markedly different processes that potentially act in

60 concert [39-41]. A highly localized genomic architecture underlying ecotypes further complicates this situation [42].

\section{(a) Can parallel emergence be discriminated from parallel introgression?}

64 We posit these factors can indeed be discriminated by predicting the ancestries for replicated 'pairs' of ecotypes distributed among sites (although patterns may also depend upon migration

66 rates among populations [43]). For hypotheses of 'independent emergence,' we would predict that genealogies with regions encapsulating targets of divergent selection [i.e., scenarios (A) or 
68 (B); figure 1], would lack shared ancestry among ecotypes, reflecting their independent origins. In a similar vein, a failure to correlate with unlinked targets of selection would also be expected

70 [12]. Thus, in the case of repeated selection upon standing genetic variation, adaptive alleles will be identical-by-descent but with flanking regions excluded (given that populations will lack

72 identical, independently-fixed haplotypes) [13,14]. Furthermore, in a scenario of independent emergence, mutations underlying adaptation may occur at different loci altogether.

74 By contrast, a 'divergence first' model with subsequent secondary contact [scenarios (C) or (D); figure 1] would imply that ancestries of ecotypes are both correlated with and shared

76 among ecotypes at those loci targeted for selection. However, genomic patterns can be difficult to disentangle from those expected under a scenario of adaptive introgression (scenario D). This

78 is because gene flow during secondary contact may effectively 'swamp' divergence developed in isolation $[12,44]$. In the absence of genomic resources (a frequent scenario for non-model

80 organisms), additional clarification can often be inferred from biogeographic context.

\section{2 (b) A case study involving Schizothorax}

We here investigate the source of adaptive genetic variation among differentially adapted pairs

84 of rheophilic freshwater fishes occupying elevational gradients in Himalayan tributaries of the Ganges and Brahmaputra rivers. Our study group (snowtrout; Cyprinidae: Schizothorax spp.) is

86 of interest in that it displays a legacy of whole-genome duplication (WGD), with variable adaptations to high elevation habitat (both phenotypic and life-historic) [45-48]. Yet, in previous

88 studies patterns of convergence are also broadly apparent [49,50]. Additionally, the rapid formation of multiple 'species flocks' has occurred within unique and isolated alpine lake

90 habitats [51-55], with recurrent divergences as an emerging consensus $[51,56]$. Here, two 
Himalayan species are of particular interest: Schizothorax progastus and S. richardsonii. Both

92 are distributed along an elevational gradient, with generalized morphologies within tributaries of the Ganges and Brahmaputra rivers converging upon 'blunt-nosed' (S. richardsonii) in upstream

94 reaches, and 'pointed-nosed' (S. progastus) in downstream reaches [52,57-59].

The 'pointed-nosed' eco-phenotype displays a more terete, streamlined shape, and

96 gradually replaces the 'blunt-nosed' form longitudinally along an elevational gradient, a pattern seemingly replicated in each of several collateral, southward-flowing tributaries in Nepal, which

98 in turn suggests the presence of ecological non-exchangeability [60]. Recent phylogenetic analyses based on mtDNA failed to support the nominal species, with relationships occurring instead at the drainage level [56]. Despite this, morphologies are consistent across drainages [51], suggesting an independent emergence of 'blunt-nosed' phenotypes (i.e., those associated 102 with S. richardsonii) within each highland drainage. Morphologically convergent ecotypes are also replicated within elevational gradients of Bhutan [61], again suggesting the formation of

104 parallel ecotypes. This suggests the potential for rapid evolution, particularly when juxtaposed with the adaptive radiation by Schizothorax within isolated Rara Lake of Nepal $[51,53]$. with a rapid, positive shift in net diversification occurring within three predominantly polyploid

108 subfamilies: Torinae, Schizopygopsinae, and Schizothoracinae, with the most profound effect in the latter. Of particular interest, all three subfamilies are endemic to the Himalayan and Qinghai-

110 Tibetan Plateau (QTP) regions, and possess life-history specializations for high-elevation existence [63]. Thus, diversification of polyploid cyprinids on the QTP and adjacent regions is

112 seemingly linked to extensive orogeny followed by periods of marked climate change [62,64 $66]$. 

how polyploidy has driven the adaptation by Schizothorax to elevational gradients. Studies

116 involving non-model polyploid species (as herein) must employ methodological paradigms that assume diploidy, yet with fundamentally divergent theoretical expectations $[67,68]$. An

118 additional complication involves the varying degrees of divergence and/ or conservation found among ohnologs (i.e., duplicated loci originating from WGD) that potentially occur in those

120 species at intermediate stages of re-diploidization [69]. One positive is that models suitable for genotyping polyploid or mixed-ploidy data [70,71] now incorporate short-read sub-genomic

122 methods (e.g., RADseq and related methods ).

The identification of genomic adaptations to elevation in Schizothorax has two trenchant

124 stumbling blocks: Drivers of morphological and phylogenetic discordance are not only numerous, but also constrained by polyploidy. To compensate, we combine novel statistical models and robust genotyping of non-model polyploids with expectations regarding how ancestries should be distributed across the genome. This allows us to address several questions 128 regarding the evolution of diverse Schizothorax lineages seemingly replicated in the Himalayan drainages of Nepal and Bhutan:

130 1. Does morphological and phylogenetic discordance in parallel Himalayan elevational gradients stem from parallel 'independent emergence (figure 1A, B), or secondary/ $132 \quad$ ongoing gene flow (figure 1C, D)?

2. If $\mathrm{A}$ or $\mathrm{B}$, do ecotypic pairs in replicated drainages show evidence of co-divergence, thus indicating a shared underlying biogeographic process (e.g., periods of QTP uplift)? 
4. Finally, is there evidence for either rapid co-divergence or hybridization as playing a role in the formation of lacustrine ecotypes?

\section{2. Methods}

\section{(a) Sampling and DNA preparation}

142 Tissue samples $(N=96)$ represent six Schizothorax species distributed throughout tributaries of the Brahmaputra and Ganges rivers (Bhutan and Nepal, respectively) (figure $2 a-c$ ). Of these,

$144 N=48$ Nepali specimens were obtained from the University of Kansas Natural History Museum (KUNHM) (figure $2 b$; table S1, S2) and represent two riverine species ['high elevation' $S$.

146 richardsonii $(N=16)$ and 'low elevation' S. progastus $(N=8)]$. These were sampled from each of the three major Nepali drainages (Kali Gandaki, Koshi, and Karnali), except for S. progastus

148 from Karnali. The remaining Nepali samples $(N=24)$ represent a land-locked lacustrine radiation endemic to Lake Rara [53]. These are: S. macrophthalmus $(N=8), S$. raraensis $(N=8)$, and $S$.

150 nepalensis $(N=8)$.

Bhutanese Schizothorax $(N=48)$ were sampled from three major Bhutanese drainages

152 (Wang Chhu, Punatsang Chhu, and Mangde Chhu: figure 2c; table S1) and identified as $S$. progastus and S. richardsonii based upon morphological diagnoses of vouchered specimens [52].

154 However, subsequent mtDNA sequence analysis has putatively identified Bhutanese $S$.

richardsonii as another convergent high-elevation specialist, S. oconnori [56], a species typically

156 found on the Qinghai-Tibetan Plateau (QTP [72,73]) within high elevation tributaries of the upper Brahmaputra River [herein referred to as the Yarlung-Tsangpo River (YLTR)]. They are

158 subsequently referred to herein as $S$. cf. oconnori (figure $2 c$ ).

Tissues were processed using the Qiagen DNeasy Blood and Tissue Kit (Qiagen, Inc.), 
160 following manufacturer's protocols. Extracts were evaluated for presence of high-molecular weight DNA using gel electrophoresis (2\% agarose) and quantified at $2 \mu 1$ per sample in $200 \mu 1$

162 assays using Qubit broad-range DNA fluorometry assays (Thermo Fisher Scientific). DNA (5001000 ng of DNA per sample in $50 \mu 1$ reactions) was then fragmented using a restriction double-

164 digest [74] with PstI (5'-CTGCAG-3') and MspI (5'-CCGG-3'). Digests were subsequently visualized on 2\% agarose gels, purified using AMPure XP beads (Beckman Coulter, Inc.), and again quantified via Qubit fluorometer.

Samples were then standardized at 100ng of digested DNA and ligated in 30 $\mu 1$ reactions

168 using T4 DNA ligase (New England Biolabs, Inc.) following manufacturer's protocols. Barcoded oligonucleotide adapters were designed and employed following Peterson et al. [74]. After a

170 second AMPure XP purification, samples were multiplexed in groups of $N=48$ and size-selected at 350-400bp (excluding adapters), using a Pippin Prep automated system (Sage Sciences).

172 Adapters for Illumina sequencing were subsequently extended via a 10-cycle PCR with Phusion high-fidelity DNA polymerase (New England Biolabs, Inc.). Final reactions were purified via

174 AMPure XP beads and standardized per submission requirements of the DNA Core Facility (University of Oregon Genomics \& Cell Characterization Facility, Eugene, OR U.S.A.).

176 Additional quality control at the core facility included fragment size analysis (to confirm successful amplification and the absence of artifacts) and qPCR (to assess the proportion of 178 sequenceable library). Sequencing pooled two $N=48$ multiplexed libraries into a single lane of 1x100 sequencing on the Illumina HiSeq 4000.

180

\section{(b) Data filtering and ploidy-aware assembly}

182 Raw reads were demultiplexed and filtered for initial assembly using IPYRAD [75]. Reads having 
$>0$ barcode mismatches or $>5$ low-quality bases were discarded, and adapter sequences trimmed

184 using the 'strict' option. Two assemblies were performed: one de novo (at an $85 \%$ identity threshold), and one using bwa to align against assembled transcriptome data (hereafter

186 'transcriptome-guided') [76]. Because the genotyping model in IPYRAD assumes diploidy [77], we used relaxed settings so as to retain assembled paralogs (e.g., electing for more stringent filtering

188 following ploidy-aware genotyping; see below). These included a minimum depth threshold of only 6 , allowing 20 heterozygous sites per consensus locus, with up to 4 alleles at a given locus 190 within an individual.

To explore potential ploidy variation in our samples, we first employed BWA [78] to 192 realign raw reads against the candidate locus catalog generated in our de novo assembly. For ploidy model selection, we then computed allelic read depths for bi-allelic sites using a de-

194 noising procedure (NQUIRE; [79] with expectations that ploidies represent allelic depths as follows: At $\sim 50 \%$ in a diploid bi-allelic heterozygote (i.e., an approximate 50:50 representation

196 of each allele in an $\mathrm{AB}$ heterozygote); at $\sim 33 \%$ or $\sim 66 \%$ for triploids (=ABB or AAB possible genotypes); and $\sim 25 \%, 50 \%$, or $75 \%$ for tetraploids (=ABBB, AABB, AAAB genotypes, 198 respectively). Log-likelihoods of the observed allelic depth distributions were extracted for Gaussian expectations under each fixed model (e.g., 2n, 3n, or 4n), then normalized by that 200 under a model of freely variable allele depths $\left(=\log \mathrm{L}_{\text {Fixed }} / \log \mathrm{L}_{\text {Free }}\right)$, with chosen models representing the greatest normalized log-likelihood. Results were employed to generate prior 202 expectations for subsequent ploidy-aware genotyping and downstream filtering.

Formatted SNPs (as .vcf) were genotyped for both de novo and transcriptome-guided

204 assemblies using the Bayesian variant calling pipeline in POLYRAD [70]. We first computed perlocus $H_{\mathrm{IND}} / H_{\mathrm{E}}$ values, a statistic representing the probability of sampling reads from two 
206 different alleles at a given locus in an individual [71]. We then simulated expected $H_{\mathrm{IND}} / H_{\mathrm{E}}$ values given the sample size and read depth distribution from the observed data, under

208 expectations of either diploidy or tetraploidy, to define threshold values under which markers are statistically consistent with Mendelian behavior as a 95\% upper-bound of the simulated

210 distribution. Because expected values differ by ploidy, we used $H_{\mathrm{IND}} / H_{\mathrm{E}}$ values averaged across loci to segregate those statistically consistent with a diploid genotype model from those

212 consistent with a tetraploid model. Using $H_{\mathrm{IND}} / H_{\mathrm{E}}$ thresholds and custom Python code (github.com/tkchafin/polyrad_scripts/filterPolyVCF.py), we partitioned genotypes for both

214 assembled datasets into loci statistically consistent with tetraploid and diploid expectations. An additional requirement was that $>50 \%$ of individuals be genotyped at an average mean per216 individual depth of $20 \mathrm{X}$.

\section{8 (c) Geometric morphometrics of Nepali fishes}

We first examined patterns of morphological convergence and divergence using geometric morphometric data [51] derived from 528 images captured from museum specimens representing all five Nepali species (for full sample metadata and KU voucher numbers, see Regmi et al. [51];

222 for those used for ddRAD, see table S2). Our analyses were restricted to the Nepali sub-tree in that voucher specimens for Bhutanese samples were not available. Briefly, 18 landmarks were

224 targeted, focusing on head morphology (i.e., snout elongation, head depth, eye/nostril placement), and body shape (origin/insertion of fins, upper/lower bases of the caudal fin, and

226 urostyle as most posterior point). Coordinates were then superimposed across samples using Generalized Procrustes Analysis implemented in GEOMORPH [80]. Full details on geometric 228 morphometric data processing, including bias and sensitivity analysis, can be found in Regmi et 
al. [51].

Procrustes-aligned coordinates were summarized using a principal component analysis (PCA) in GEOMORPH [80]. We then conducted a linear discriminant analysis (LDA) using the

MASS R package [81], maximizing discriminant capacity with $80 \%$ of samples as a training set, and group classifications specified as species $\mathrm{X}$ drainage.

\section{(d) Phylogenetic relationships}

236 Given that most phylogenomic methods cannot take into account polyploid SNP genotypes [82], our initial phylogenies were instead built using an alignment-free method that computes

238 distances from the intersection of $k$-mer distributions in unaligned reads [83,84]. Matrices of $k$ mer distances were then used to infer a phylogenetic tree with branch lengths using FASTME $240 \quad[85]$.

The resulting topology was additionally contrasted with that inferred under a

242 polymorphism-aware (POMO) model inferred in IQ-TREE [86,87], as evaluated across 1,000 ultrafast bootstraps, with a GTR substitution model, gamma-distributed rates ( $N=4$ categories),

244 and a virtual population size of 19.

\section{6 (e) Population structure and molecular clustering}

Most widely used clustering or 'assignment test' methods that examine population structure are

248 either inappropriate for polyploid data or cannot handle mixed-ploidy genotypes [67]. However, STRUCTURE is robust in both situations [88,89], though more computationally intensive than

250 alternatives. We thus coded our mixed-ploidy genotypes as input for STRUCTURE, following recommendations of Meirmans et al. [67] and Stift et al. [89], using 10 replicates each of $K$ 
252 values (= \# sub-populations) ranging from $K=1$ to $K=20$. Analyses were additionally replicated across de novo and transcriptome-guided assemblies, using a total MCMC length of 100,000

254 iterations following a 50,000-iteration burn-in. Input files were generated using polyVCFtoStructure.py (github.com/tkchafin/polyrad_scripts), and results were

256 aggregated/visualized using the CLUMPAK pipeline [90], with selection of optimal $K$ following the Evanno method [91]. Final visualizations aligned the ancestry proportion bar plots aligned to 258 our SKMER phylogeny using code from Martin et al. [92].

Results were contrasted with ordination via discriminant analysis of principal

260 components (DAPC), performed in ADEGENET [93,94]. Samples were stratified according to species X basin assignment (e.g., S. progastus from Wang Chhu), and with analyses performed

262 in three ways: 1) globally; 2) Nepal-only; and 3) Bhutan-only. The number of principal components (PCs) retained in each case was determined using the xvalDapc function as a cross-

264 validation approach, with the optimal number of the root-mean-square-error (RMSE) of assignment derived from a $10 \%$ subset (with the remaining $90 \%$ serving as a training set). This

266 was accomplished across 30 replicates per level of PC retention, up to a maximum of 300 retained PCs, resulting in 20 (globally-), 10 (Bhutanese-), and 5 (Nepali-) retained PCs.

\section{(f) Modeling population mixture}

270 We assessed hybridization within Nepali and Bhutanese sub-trees using TREEMIX [95], with a global search across numbers of migration events $(m)$ ranging from $0-5$. Because markers are

272 assumed diploid, migration analyses were only performed on markers statistically-fitting diploid expectations, as designated by POLYRAD [70]. Optimal values of $m$ for each subtree were

274 determined from rates of log-likelihood change as computed in OPTM [96], which generates an 
276 deviation (e.g., the 'Evanno' method; Evanno et al. 2005). Independent replicates on the full dataset yielded identical likelihoods for some $m$-values (i.e., yielding an undefined $\Delta \mathrm{M}$ ) and,

278 given this, we assessed variability using 100 bootstrap pseudoreplicates per migration model. To additionally discriminate among divergence scenarios among Nepali S. richardsonii and S.

280 progastus, we calculated a 4-taxon Patterson's $D$ statistic and admixture fractions ( $f_{4}$-ratio)

$[97,98]$. Both are formulated to test an enrichment of shared-derived site patterns between either 282 component of a lineage pair (P1 or P2), and a third lineage (P3) relative to an outgroup. The assumed phylogenetic structure would be: (((P1, P2), P3), P4). Our interest was in shared

284 patterns, both at the level of "conspecifics" among drainages and "heterospecifics" within drainage, and our tests were conducted such that P1 and P2 were defined by river [e.g., (richX, progX), rich $\mathrm{Y})$, Outgroup), where $\mathrm{X}$ and $\mathrm{Y}$ represent different drainages], and where $\mathrm{P} 1$ and $\mathrm{P} 2$ were defined per taxon-assignment [e.g., (richX, richY), progX), Outgroup)]. The outgroup in 288 all cases was S. cf. oconnori from Bhutan.

290 (g) Testing models of co-divergence

To test if shared (e.g. geomorphic) events may have driven co-divergence, we used the program

292 ECOEVOLITY [99], which employs a Bayesian method to compute probabilities on the number of independent divergences across a series of pairwise comparisons. Because ECOEvOLITY is most 294 consistent when analyzing both constant and polymorphic sites [99,100], we sampled full-locus alignments (excluding sites with either $>25 \%$ missing data globally or per-population) using the 296 phylip2ecoevolity.pl script from Chafin et al. [101]. The event model followed a Dirichlet process, with the prior probability distribution for the number of divergence events skewed 
towards a model of complete independence (i.e. no co-divergence). Posterior probabilities were computed over a total of 75,000 MCMC iterations, with a sampling frequency every $50^{\text {th }}$ iteration. Burn-in was automatically computed using an automated iterative procedure which selected the number of burn-in iterations which maximized the effective sample size (ESS).

\section{(h) Testing patterns of selection and locus-wise differentiation}

304 Here we sought loci strongly associating with axes of population differentiation, and therefore employed the program PCADAPT [102] to identify loci putatively associated with differentiation of $S$. richardsonii and S. progastus. Detecting loci under selection is a persistent methodological gap in those studies examining polyploid SNP data [67] and, given this, we restricted our analysis to transcriptome-mapped loci that could appropriately be genotyped as diploid [70]. Analyses were performed by partitioning the data so as to target specific divergence events: $S$. richardsonii X S. progastus (Gandaki); S. richardsonii X S. progastus (Koshi); S. richardsonii X Lake Rara (S. macrophthalmus, S. raraensis, and S. nepalensis); S. nepalensis X S.

312 macrophthalmus+raraensis; and S. progastus (Bhutan) X S. cf. oconnori. Loci were additionally restricted to those with a minor allele frequency $(\mathrm{MAF})>0.05$, with significance assessed using

$314 \alpha=0.01$ adjusted via Bonferroni correction (where $N$ tests $=N$ SNPs). Transcripts encapsulating outlier SNPs were additionally annotated with gene ontology (GO) terms for biological functions

316 using the BLAST2GO pipeline [103], searching against the SWISS-PROT and InterPro databases $[104,105]$. Redundancy was reduced in GO-term annotations by measuring semantic 318 similarity using RRVGO [106] and the Danio rerio organismal database.

We additionally contrasted population pairs (delineated as above), using a ploidyappropriate $F_{\mathrm{ST}}$ measure. We calculated heterozygosity (i.e. 'gene' diversity [92]) as: $H_{\mathrm{s}}=1-$ 
$\Sigma p_{i}^{2}$, where $p_{i}$ is the frequency of allele $i$ [107]. Although in diploids this measure is often

322 referred to as 'expected heterozygosity,' it does not have the same relationship with heterozygosity across ploidies [67]. Finally, we calculated genetic distance as Jost's $D$ [108], as

324 well as absolute distance $\left(D_{\mathrm{XY}}\right)$ for each SNP based on allele frequencies and summarized across loci as an arithmetic mean [109].

\section{(i) Partitioned analysis across subsets of loci}

328 As a final test of the hypothesis that divergence between pairs of S. richardsonii-S. progastus represents isolation prior to secondary hybridization, we performed a partitioned analysis across 330 subsets of our data. Our prediction was as follows: If differential adaptation reflects a retention of minor genomic regions from secondary introgression (i.e., as opposed to arising

332 independently), then disparate populations of $S$. richardsonii would be more similar at loci for which drainage pairs (richardsonii-progastus) are highly diverged. We diagnosed such loci in

334 two ways: First, we computed a ratio of $D_{\mathrm{XY}}$ between richardsonii-progastus pairs within Koshi and Gandaki rivers, and $D_{\mathrm{XY}}$ of $S$. richardsonii populations among drainages. Here, a value less

336 than 1.0 indicates a locus for which richardsonii-progastus pairs are more similar than richardsonii-richardsonii comparisons. A value $>1.0$ indicates a locus for which richardsonii-

338 progastus are more highly diverged. If loci with a $D_{\mathrm{XY}}$ ratio $>1.0$ originated from hybridization, genetic relationships among those loci should reflect a conspecific phylogeny. To assess the

340 latter, we replicated TREEMIX analyses (as above) for loci $>1.0$ and $<1.0$. As a secondary test, we also partitioned locus-wise richardsonii-progastus $F_{\mathrm{ST}}$ into four groups, each receiving the same

342 analytical treatment as the $D_{\mathrm{XY}}$ ratio partitions: 1) $F_{\mathrm{ST}}=0.0-0.249$; 2) $0.25-0.49$; 3) $0.50-0.749$; and 4) $0.75-1.0$. 


\section{Results}

\section{(a) Sequence assembly and genotyping}

Prior to downstream filtering, we assembled $N=48,350$ and 14,301 SNPs for de novo and

348 transcriptome-guided assemblies, respectively. Allele depths for biallelic sites were

overwhelmingly trimodal, with NQUIRE likelihoods suggesting tetraploidy across all study taxa

350 (figure 3). Raw outputs from de novo and transcriptome-aligned assemblies resulted in 48,350 and 14,301 loci, respectively (table S3). Three samples failed to yield genotype data for $>=50 \%$

352 of loci and were removed. Simulated expectations in POLYRAD yielded $H_{\mathrm{IND}} / H_{\mathrm{E}}$ thresholds of 0.52 (diploid) and 0.65 (tetraploid). Post-filtering datasets consisted of 5,601 (2n) and 5,284 (4n)

354 transcriptome-mapped, and 15,547 (2n) and 19,772 de novo SNPs (table S3). For each assembly method, these were divided into files containing all loci as well as subsets containing only those

356 statistically consistent with a diploid model. Scripts for formatting datafiles and outputs can be found at: github.com/tkchafin/polyrad_scripts.

\section{(b) Contrasting molecular and geometric morphometric results}

360 Morphological DAPC showed a marked convergence of S. richardsonii and S. progastus body shapes, regardless of origin, with Lake Rara taxa (S. macrophthalmus, S. nepalensis, and S.

362 raraensis) having weak or no differentiation (figure 4). Among the latter, S. nepalensis was most intermediate between a 'Lake Rara' cluster, and that for S. richardsonii (and to a lesser extent, $S$.

364 progastus). This contrasted sharply with the clustering of Nepali specimens based solely on ddRAD data (figure $5 a, c$ ), where the predominant relationship was by drainage (e.g., with Koshi 366 and Gandaki S. progastus and S. richardsonii grouping together). 
368 richardsonii from the Koshi and Gandaki rivers being monophyletic in the alignment-free phylogeny (figure 6a) and agreeing approximately with STRUCTURE-inferred assignment

370 probabilities (figure $6 b$ ). Optimal Evanno-derived $K$ in the latter identified peaks in DeltaK at $K=3$ and $K=7$. The former yielded a homogenous Nepali sub-tree, with only the Koshi River

372 samples somewhat distinct (figure $6 a, b$ ), whereas $K=7$ reveals weak differentiation, with mixed assignment spanning basins.

Inferred edges in TREEMIX suggested migration between S. progastus of the Koshi and

Gandaki rivers, as well as between $S$. progastus of the Koshi with $S$. raraensis and $S$.

376 macrophthalmus of Lake Rara (figure 6c). However, the latter may be mis-ascribed, particularly given the absence of sampling for S. progastus from the Karnali River. Furthermore, migration

378 edges in TREEMIX may also explain the mixed inter-drainage assignment seen in STRUCTURE, as well as the non-monophyly of Koshi River richardsonii-progastus in our PoMo analysis (figure 380 7).

Bhutanese Schizothorax spp. differed in that no clear delineations were found between

382 high- and low-elevation clades in S. progastus, and with clustering instead reflecting specieslevel assignments (figure 5, 6b). STRUCTURE results suggested mixed assignment of $S$. progastus

384 and S. cf. oconnori, particularly in the Wang Chhu where both de novo and transcriptome-guided results agreed (figure 6b). TREEMIX results also revealed evidence in multiple sub-basins for

386 exchange across species boundaries (figure $6 c$ and S1). Of note, mixed assignment was also observed between $S$. progastus (Bhutan) with those from Nepal (figure $6 c$ ). We could not test

388 whether this reflects retained ancestral variation (i.e., prior to divergence of Ganges and Brahmaputra rivers), or more contemporary mixture. Patterson's $D$-statistic likewise supported 
this mixed ancestry, both at the level of conspecifics among drainages and heterospecifics within drainages (table S3).

\section{(c) Co-divergence analysis}

394 Co-divergence analysis rejected co-divergence for all riverine pairwise comparisons for both Nepal and Bhutan (figure 8). One notable exception was the inferred simultaneous divergence of

396 the 'Lake Rara' lacustrine radiation (here represented as two comparisons: S. macrophthalmus $\mathrm{x}$ S. raraensis $+S$. nepalensis; and S. raraensis x S. nepalensis; figure 8a). Here, a model of 4 398 divergences was selected for Nepal (posterior probability > 0.9; figure 8c), with the relative timing for this radiation exceptionally recent compared to those inferred for within-drainage

400 comparisons. We note, however, that inferred divergence times are likely skewed by introgression (e.g. figure 6c), but that the exact nature of this effect is unclear [101]. Parameter 402 estimates for all analyses post burn-in were $>600$.

\section{4 (d) Locus-wise differentiation and outlier analysis}

The greatest number of significant SNPs following Bonferroni-correction occurred in outlier 406 analysis involving Koshi and Gandaki S. richardsonii-progastus pairs, and from the comparison of $S$. progastus and S. cf. oconnori from Bhutan (i.e. $N=531$ and 54, respectively; figure $\mathrm{S} 2 a$ ). Of

408 these, the most substantial number of overlapping SNPs was found among Koshi and Gandaki comparisons. Outliers in both cases had higher $F_{\mathrm{ST}}$ than did the genome-wide distribution

410 involving de novo or transcriptome-guided assemblies. This pattern was not repeated in the same loci for Bhutan (figure S2b), although outlier loci in Bhutan did share a negative relationship of 412 gene diversity $\left(H_{\mathrm{E}}\right)$, as compared to $S$. richardsonii-progastus $F_{\mathrm{ST}}$ (figure $\mathrm{S} 2 c$ ). Outlier $F_{\mathrm{ST}}$ for $S$. 
richardsonii-progastus was correlated in the Gandaki versus Koshi rivers, but with no

414 discernible relationship with the same measure when compared to Karnali River S. richardsonii and Lake Rara species, Bhutanese S. progastus-oconnori, nor among Bhutanese populations of

416 only S. progastus (figure S3). Relationships among different locus-differentiation statistics otherwise occurred per theoretical expectations (figure S4). Hence only comparisons (above) are

418 presented for $F_{\mathrm{ST}}$. Relating $D_{\mathrm{XY}}$ ratios to $D_{\mathrm{XO}}$ showed that high values were likely driven by near-zero distances among S. richardsonii pairs for a subset of loci (figure S5), in line with

420 evidence from the $D$-statistics indicating shared inter-drainage ancestry among conspecifics (table S3).

Although $\sim 75 \%$ of outlier transcripts could not be assigned candidate protein products, gene ontology (GO) term enrichment for shared outliers revealed a number of related biological

424 processes, including anatomical structure formation (GO: 0048646), up-regulation of phosphoprotein phosphatase activity (GO: 0032516), and up-regulation of G protein coupled

426 receptor signaling (GO: 0045745)(figure S2d). The few outlier transcripts that could be assigned candidate proteins in the overlapping Gandaki-Koshi set were: Aurora Kinase A (AURKA), Zinc

428 Finger SWIM Domain Containig Protein 6 (ZSWIM6), Adhesion G protein-coupled receptor A3 $(A D G R A 3)$, and Caspase $\mathrm{B}(C A S P B)$.

\section{(e) Partitioned ancestry and mixture analyses}

432 Loci for which richardsonii-richardsonii divergence was greater than richardsonii-progastus (i.e., $D_{\mathrm{XY}}$ ratio $<1.0$; figure $9 a$ ) occurred in drainages irrespective of ecomorphological taxon-

434 assignment and corresponded to $\sim 68 \%$. The remaining $\sim 32 \%$ yielded groupings consistent with species-level taxonomy, but with migration among species suggested within the Gandaki and 
436 Koshi rivers (figure $9 a$ ). Repeating the same analysis across loci binned by $F_{\text {ST }}$ yielded a transition from drainage-level at low values (with migration among mid-highland S. progastus)

438 towards species-level at high values (with migration within drainages) (figure $9 b$ ). This pattern was consistent when loci were binned with $F_{\mathrm{ST}}$ estimates derived either from $S$. richardsoniiprogastus comparisons in the Gandaki or the Koshi, although the transition towards species-level grouping was slightly protracted in the latter (figure $9 b$ ).

\section{Discussion}

444 We apply genome-wide SNP data and ploidy-aware genotyping to demonstrate that genetic and morphologically distinct Schizothorax forms in Himalayan tributaries evolved prior to secondary

446 gene flow, rather than as a parallel emergence of elevational forms. In addition, highland specialists in Nepal converged strongly onto a singular phenotype that was recapitulated in

448 phylogenetic patterns at presumed targets of selection. However, neutral variation showed signs within each basin of homogenization among elevational pairs (S. richardsonii and S. progastus),

450 suggesting a breakdown of reproductive isolation. In Bhutan, elevational pairs (S. progastus and S. $c f$. oconnori) exhibited low-level as mixture, suggesting that elevational pairs possess either

452 greater reproductive fidelity or instead represent an earlier stage of homogenization via secondary gene flow.

\section{(a) Parallel divergence versus parallel hybridization in Nepali snowtrout}

456 Genome-wide relationships among Nepali and Bhutanese Schizothorax give the appearance of recurrently emerging ecotypes, with repeated colonization of highland habitats from a mid- 
460 broader pattern of convergence among high-elevation specialists [50,62]. Indeed, WGD-derived adaptive potential may have played a role in the parallel colonization of highland habitats by $S$.

462 richardsonii in the Ganges tributaries of Nepal, and $S . c f$. oconnori in the Brahmaputra tributaries of Bhutan, although we note that the current study lacks geometric morphometric data 464 for the latter.

In the case of elevational Schizothorax pairs in Nepal, we found that dominant ancestries 466 shifted from grouping at the drainage-level (based on scarcely differentiated/ "neutral" loci) (irrespective of eco-morphology) towards the conspecific-level (via strongly

468 differentiated/selected loci). However, this raises an additional question: How are adaptive phenotypes retained despite introgression being reflected within most of the genome? Here, one 470 potential is that an allopolyploid origin of WGD in Schizothorax conflate the signal of hybridization. However, a lack of sub-genome divergence was found in S. oconnori [110], as

472 would be expected under allopolyploidy.

It is also possible that polyploidy facilitates a greater degree of genomic exchange when

474 compared with reproductively isolated diploid species [111]. For example, ploidy has been suggested to promoting introgression in diploid-tetraploid crosses of Arabidopsis, due to a

476 circumvention of dosage-mediated postzygotic isolation [112-114]. Increased introgression has also been supported among tetraploid-tetraploid crosses (as herein), with an increase in local

478 recombination rates as one potential mechanism. As ploidy increases, there is a relaxation of linkage as a component of purifying selection [115,116]. Similarly, increased dosage may 'mask' 480 deleterious loads, especially in young polyploid species [117,118]. Given the young age of WGD estimated for S. oconnori [110], these predictions implicate a genomic landscape vastly more 
482 porous than might be expected in their diploid counterparts [114]. This may also be an underappreciated mechanism promoting the hypothesized increased adaptability of polyploids to 484 stressful or novel environments $[119,120]$.

\section{6 (b) Varying rates of hybridization among drainages}

In contrast to the substantially permeable genomic landscape seen among $S$. richardsonii and $S$.

progastus pairs in Nepal, we saw a much smaller signature of gene flow in Bhutanese elevational pairs (S. progastus, S. cf. oconnori). In addition to gene flow obscuring species boundaries

[92,121], contrasts between Himalayan streams and extreme freshwater habitats in the American Southwest [121-123] also implicate the potential for anthropogenically mediated hybridization.

492 Here, 'extinction vortices' may be driven by a coupling of potentially maladaptive hybridization combined with declining population sizes. This provides a backdrop against which climatic

494 expectations of shrinking habitats for vulnerable highland species such as $S$. richardsonii can be contrasted [124]. cannot be inferred from our data, nor can the environmental covariates potentially modulating

498 species boundaries be inferred without further work. Given the potential for seasonal migratory behavior in Schizothorax [73,127], hydropower dams will disrupt movements, thus inadvertently

500 promoting interspecific contact. Here, we again emphasize parallels with the heavily-modified and regulated rivers of western North America, where water policy and impoundments promote

502 hybridization [122,128], define habitat suitability [129], and alter environmental cues [130]. Though both countries have a high percentage of protected areas, our results suggest that 504 anthropogenically-mediated hybridization represents an additional dimension to consider when 
balancing freshwater conservation planning [131,132].

506

\section{(c) High-elevation adaptation}

508 Although we found relatively little overlap in putative targets of selection (figure S2a), our reduced-representation approach only surveyed a small percentage of transcripts, with poor

510 success in establishing functional annotations. Molecular convergence among high-elevation populations has been observed in disparate human populations [133], and even among humans

512 and their domesticated species [134]. Other studies in Schizothorax have shown an array of candidate genes underscoring adaptations to hypoxic and ultraviolet conditions associated with

514 elevation [135].

Schizothoracine fishes in general have been characterized as species similarly to trout

516 (Salmonidae) adapted to torrential flows, with positioning in rapid currents facilitated by body shape [136]. A longitudinal survey of Nepali assemblages showed replacement of S. richardsonii

518 by $S$. progastus at decreasing elevations [60], suggesting a role for factors such as dissolved oxygen and flow rates [137]. Turnover and narrow elevational ranges are found in other

520 Himalayan taxa as well $[138,139]$. Specialized sucker-like adaptations are present in $S$.

richardsonii but absent in S. progastus [60], and species richness in Schizothorax is greater at

522 mid-elevation [140], seemingly corroborating this relationship Schizothorax.

An interesting case of adaptation which we did not explore fully herein is that of the

524 putative species flock in Lake Rara (figure 8a). There, species overlap in geometric morphometric space (figure 3), yet display marked differences in mouth morphology, gill raker

526 shape, spawning microhabitat choice, and diet (with S. raraensis insectivorous, S. nepalensis herbivorous, and S. macrophthalmus planktivorous) [53]. We found them genetically 
528 indistinguishable across several analyses, in agreement with previous studies [54,56], though this is unsurprising given their apparent recent and rapid diversification (figure 8) [101].

\section{Conclusions}

532 Our results indicate that population genomics can be accomplished in a statistically appropriate manner using non-model polyploid species with relatively minor adjustments to the traditional

534 molecular ecology workflow. However, several limitations were encountered (such as the lack of ploidy-aware methods for outlier detection), signaling a need for further development. Despite

536 these limitations, we were able to disentangle the parallel evolution of Schizothorax species in Himalayan tributaries of the Ganges and Brahmaputra rivers, and with recurrent processes

538 implicated at differing timescales: convergent adaptation towards high-elevation environments among major drainages (e.g., Ganges versus Brahmaputra), and parallel selection against

540 introgressive homogenization within drainages. With regards to the latter, we found heterogeneous levels of admixture among populations. Finally, we rejected the hypothesis of co-

542 divergence between highland and mid-highland riverine forms, yet found the lacustrine radiation in Lake Rara to be both recent, and rapid.

Ethics. All methods were performed in accordance with relevant guidelines and regulations.

546 Bhutanese collecting permits were in conjunction with the National Research \& Development Centre for Riverine and Lake Fisheries (NRDCR\&LF), Ministry of Agriculture \& Forests

548 (MoAF), Royal Government of Bhutan. The export of fin clips was authorized through a Material Transfer Agreement (MTA) provided by the National Biodiversity Centre (NBC), with 550 additional approvals provided by the Department of Forests \& Park Services (DoFPs) and 
Bhutan Agricultural and Food Regulatory Authority (BAFRA). Sampling protocols were

552 approved by the University of Arkansas Institutional Animal Care and Use Committee

(UA_IACUC_17064). The study was also carried out in compliance with ARRIVE guidelines

554 (https://arriveguidelines.org).

556 Data and code accessibility. Raw sequence data will be made available via the NCBI Short Read Archive (SRA) pending acceptance, under BioProject PRJNA759907. Assembled datasets 558 and input files are available in the Open Science Framework repository (doi:

10.17605/OSF.IO/TMJFK). Relevant code for this research work are stored in GitHub:

560 github.com/tkchafin/polyrad_scripts and github.com/tkchafin/scripts, and have been archived within the Zenodo repositories doi: 10.5281/zenodo.5393418 and doi: 10.5281/zenodo.5181290.

Authors contributions. All contributed to conceptualization and study design. D.R.E. collected

564 samples in Nepal. S. T., K. W., S. D., P. N., S. N., C. L., and G. P. K. coordinated and supervised field work in Bhutan. S.T., K.W., M.E.D., M.R.D, S. D., P. N., S. N., C. L., G. P. K., and T.K.C. 566 collected samples in Bhutan. B.R. collected and curated geometric morphometric data. M.E.D. and M.R.D. generated molecular data. T.K.C. wrote necessary codes and performed

568 bioinformatic work. B.R. and T.K.C. analyzed data. T.K.C. generated figures and drafted the manuscript. All authors contributed to revising the final product and subsequently approved its 570 submission.

572 Competing interests. We declare we have no competing interests. 
574 Funding. The National Research Centre for Riverine and Lake Fisheries (NRCRLF, Bhutan) provided logistic support and personnel with which to sample fishes. Analytical resources were

576 provided by the Arkansas Economic Development Commission (Arkansas Settlement Proceeds Act of 2000) and the Arkansas High Performance Computing Center (AHPCC). Computational

578 support was also provided by the U.S. National Science Foundation (NSF) funded XSEDE Jetstream cloud (award \#TG-BIO200074 to T.K.C.). This research was made possible through

580 generous endowments to the University of Arkansas: The Bruker Professorship in Life Sciences (M.R.D.), the 21 st Century Chair in Global Change Biology (M.E.D.), Distinguished Doctoral

582 Fellowship award (T.K.C.), and Graduate Teaching Assistantships (K.W., T.K.C.), all of which provided salaries and/or research funds to complete this study. T. K. C. received additional

584 support via an NSF Postdoctoral Fellowship in Biology under Grant No. DBI: 2010774. Any opinions, findings, and conclusions or recommendations expressed in this material are those of

586 the author(s) and do not necessarily reflect the views of the funding agencies nor affiliated organizations.

Acknowledgments. Museum specimens and tissue samples for Nepal were obtained from the

590 University of Kansas Natural History Museum (KUNHM; https://biodiversity.ku.edu/ichthyology/collections), vouchers KU:KUIT:27806-27815, 27885-

592 27887, 29043, 29050, 29233, 29234, and 29236-29238 (for specific tissue numbers, see table s2). We thank Curator Leo Smith and Collection Manager Andrew Bentley for tissue loans and 594 use of imaging facilities at KUNHM. Nepali samples were originally collected by D.R.E., as funded by a Fulbright Scholarship, the Explorers Club, and the National Geographic Society 596 (NGEO) Committee for Research. 


\section{References}

1. Schluter D, Nagel LM. 1995 Parallel speciation by natural selection. Am. Nat. 146, 292301.

2. Schluter D, Conte GL. 2009 Genetics and ecological speciation. Proc. Natl. Acad. Sci.

602 106, 9955-9962. (doi:10.1073/pnas.0901264106)

3. Rundle HD, Nosil P. 2005 Ecological speciation. Ecol. Lett. 8, 336-352.

604

4. Hendry AP, Nosil P, Rieseberg LH. 2007 The speed of ecological speciation. Funct. Ecol.

5. Barrett RDH, Schluter D. 2008 Adaptation from standing genetic variation. Trends Ecol.

6. Pearse DE, Miller MR, Abadía-Cardoso A, Garza JC. 2014 Rapid parallel evolution of standing variation in a single, complex, genomic region is associated with life history in steelhead/rainbow trout. Proc. R. Soc. B Biol. Sci. 281. (doi:10.1098/rspb.2014.0012)

7. Meier JI, Marques DA, Mwaiko S, Wagner CE, Excoffier L, Seehausen O. 2017 Ancient hybridization fuels rapid cichlid fish adaptive radiations. Nat. Commun. 8, 14363. (doi:10.1038/ncomms14363)

8. Meier JI et al. 2019 The coincidence of ecological opportunity with hybridization explains rapid adaptive radiation in Lake Mweru cichlid fishes. Nat. Commun. 10, 5391. (doi:10.1038/s41467-019-13278-z)

618 9. Lucek K, Lemoine M, Seehausen O. 2014 Contemporary ecotypic divergence during a recent range expansion was facilitated by adaptive introgression. J. Evol. Biol. 27, 22332248. (doi:10.1111/jeb.12475)

10. Edelman NB, Frandsen PB, Miyagi M, Clavijo B, Davey J, Dikow RB, García-accinelli G, Belleghem SM Van, Patterson N. 2019 Genomic architecture of introgression shape a butterfly radiation. Science 599, 594-599.

624 11. Dasmahapatra KK et al. 2012 Butterfly genome reveals promiscuous exchange of mimicry adaptations among species. Nature (doi:10.1038/nature11041)

626 12. Van Belleghem SM, Vangestel C, De Wolf K, De Corte Z, Möst M, Rastas P, De Meester L, Hendrickx F. 2018 Evolution at two time frames: Polymorphisms from an ancient singular divergence event fuel contemporary parallel evolution. PLoS Genet. 14, e1007796. (doi:10.1101/255554)

632 14. Roesti M, Gavrilets S, Hendry AP, Salzburger W, Berner D. 2014 The genomic signature of parallel adaptation from shared genetic variation. Mol. Ecol. 23, 3944-3956. 
15. Nosil P, Funk DJ, Ortiz-Barrientos D. 2009 Divergent selection and heterogeneous

16. Via S. 2009 Natural selection in action during speciation. Proc. Natl. Acad. Sci. U. S. A.

17. Nosil P, Feder JL. 2012 Genomic divergence during speciation: causes and consequences.

(1)

18. Nosil P, Parchman TL, Feder JL, Gompert Z. 2012 Do highly divergent loci reside in genomic regions affecting reproductive isolation? A test using next-generation sequence data in Timema stick insects. BMC Evol. Biol. 12, 164. (doi:10.1186/1471-2148-12-164)

644 19. Yeaman S, Whitlock MC. 2011 The genetic architecture of adaptation under migrationselection balance. Evolution 65, 1897-1911. (doi:10.1111/j.1558-5646.2011.01269.x)

646 20. Zhang X, Rayner JG, Blaxter M, Bailey NW. 2021 Rapid parallel adaptation despite gene flow in silent crickets. Nat. Commun. 12. (doi:10.1038/s41467-020-20263-4)

648 21. Larson WA, Dann TH, Limborg MT, McKinney GJ, Seeb JE, Seeb LW. 2019 Parallel signatures of selection at genomic islands of divergence and the major histocompatibility complex in ecotypes of sockeye salmon across Alaska. Mol. Ecol. 28, 2254-2271. (doi:10.1111/mec.15082)

22. Pearse DE et al. 2019 Sex-dependent dominance maintains migration supergene in rainbow trout. Nat. Ecol. Evol. 3, 1731-1742. (doi:10.1038/s41559-019-1044-6)

23. Feder JL, Flaxman SM, Egan SP, Nosil P. 2013 Hybridization and the build-up of genomic divergence during speciation. J. Evol. Biol. 26, 261-266. (doi:10.1111/jeb.12009)

24. Flaxman SM, Feder JL, Nosil P. 2013 Genetic hitchhiking and the dynamic buildup of

25. Via S. 2012 Divergence hitchhiking and the spread of genomic isolation during ecological speciation-with-gene-flow. Philos. Trans. R. Soc. B Biol. Sci. 367, 451-460. (doi:10.1098/rstb.2011.0260)

26. Via S, West J. 2008 The genetic mosaic suggests a new role for hitchhiking in ecological genomic divergence during speciation with gene flow. Evolution 67, 2577-2591. (doi:10.1111/evo.12055)

27. Cruickshank TE, Hahn MW. 2014 Reanalysis suggests that genomic islands of speciation are due to reduced diversity, not reduced gene flow. Mol. Ecol. 23, 3133-3157. (doi:10.1111/mec.12796)

668 28. Noor MAF, Bennett SM. 2009 Islands of speciation or mirages in the desert? Examining the role of restricted recombination in maintaining species. Heredity 103, 439-444.

29. Guerrero RF, Hahn MW. 2017 Speciation as a sieve for ancestral polymorphism. Mol.

30. Quesada H, Posada D, Caballero A, Morán P, Rolán-Alvarez E. 2007 Phylogenetic evidence for multiple sympatric ecological diversification in a marine snail. Evolution 61, 
1600-1612. (doi:10.1111/j.1558-5646.2007.00135.x)

676 31. Bierne N, Gagnaire PA, David P. 2013 The geography of introgression in a patchy environment and the thorn in the side of ecological speciation. Curr. Zool. 59, 72-86.

678 32. Roux C, Fraïsse C, Castric V, Vekemans X, Pogson GH, Bierne N. 2014 Can we continue to neglect genomic variation in introgression rates when inferring the history of

680 speciation? A case study in a Mytilus hybrid zone. J. Evol. Biol. 27, 1662-1675. (doi:10.1111/jeb.12425)

682 33. Martin BT, Douglas MR, Chafin TK, Placyk JS, Birkhead RD, Phillips CA, Douglas ME. 2019 Contrasting signatures of introgression in North American box turtle (Terrapene spp.) contact zones. Mol. Ecol. 29, 4186-4202. (doi:10.1101/752196)

34. Payseur BA, Rieseberg LH. 2016 A genomic perspective on hybridization and speciation. Mol. Ecol. 25, 2337-2360. (doi:10.1111/mec.13557)

35. Runemark A, Fernández LP, Eroukhmanoff F, Sætre GP. 2018 Genomic contingencies and the potential for local adaptation in a hybrid species. Am. Nat. 192, 10-22. (doi:10.1086/697563)

690 36. Edelaar P, Siepielski AM, Clobert J. 2008 Matching habitat choice causes directed gene flow: A neglected dimension in evolution and ecology. Evolution 62, 2462-2472.

$692 \quad$ (doi:10.1111/j.1558-5646.2008.00459.x)

37. Bassham S, Catchen J, Lescak E, von Hippel FA, Cresko WA. 2018 Repeated selection of alternatively adapted haplotypes creates sweeping genomic remodeling in stickleback. Genetics 209, 921-939. (doi:10.1534/genetics.117.300610)

696 38. Wang L, Josephs EB, Lee KM, Roberts LM, Rellán-Álvarez R, Ross-Ibarra J, Hufford MB. 2021 Molecular parallelism underlies convergent highland adaptation of maize landraces. Mol. Biol. Evol. , msab119. (doi:10.1093/molbev/msab119)

39. Lee KM, Coop G. 2017 Distinguishing among modes of convergent adaptation using population genomic data. Genetics 207, 1591-1619.

40. Whiting JR, Fraser BA. 2020 Contingent convergence: The ability to detect convergent genomic evolution is dependent on population size and migration. G3 Genes, Genomes, Genet. 10, 677-693. (doi:10.1534/g3.119.400970)

704 41. Taylor RS, Manseau M, Horn RL, Keobouasone S, Golding GB, Wilson PJ. 2020 The role of introgression and ecotypic parallelism in delineating intraspecific conservation units. Mol. Ecol. 29, 2793-2809. (doi:10.1111/mec.15522)

42. Thompson NF, Anderson EC, Clemento AJ, Campbell MA, Pearse DE, Hearsey JW, Kinziger AP, Garza JC. 2020 A complex phenotype in salmon controlled by a simple change in migratory timing. Science 370, 609-613. (doi:10.1126/SCIENCE.ABA9059)

710 43. Pérez-Pereira N, Quesada H, Caballero A. 2017 Can parallel ecological speciation be detected with phylogenetic analyses? Mol. Phylogenet. Evol. 116, 149-156. (doi:10.1016/j.ympev.2017.08.019)

44. Le Moan A, Gagnaire PA, Bonhomme F. 2016 Parallel genetic divergence among coastalmarine ecotype pairs of European anchovy explained by differential introgression after 
716 45. Qi D, Li T, Zhao X, Guo S, Li J. 2006 Mitochondrial cytochrome b sequence variation and phylogenetics of the highly specialized Schizothoracine fishes (Teleostei: Cyprinidae)

718 in the Qinghai-Tibet plateau. Biochem. Genet. 44, 270-285. (doi:10.1007/s10528-0069022-5)

720 46. Zhang D et al. 2017 Genetic adaptation of schizothoracine fish to the phased uplifting of the Qinghai-Tibetan Plateau. G3 Genes, Genomes, Genet. 7, 1267-1276.

$722 \quad$ (doi:10.1534/g3.116.038406)

724

47. Zhang C et al. 2018 Adaptive evolution of the Eda gene and scales loss in schizothoracine fishes in response to uplift of the tibetan plateau. Int. J. Mol. Sci. 19, 1-14. (doi:10.3390/ijms19102953)

726 48. Guan L, Chi W, Xiao W, Chen L, He S. 2014 Analysis of hypoxia-inducible factor alpha polyploidization reveals adaptation to Tibetan plateau in the evolution of schizothoracine fish. BMC Evol. Biol. 14, 17-21. (doi:10.1186/s12862-014-0192-1)

49. Tang Y, Li C, Wanghe K, Feng C, Tong C, Tian F, Zhao K. 2019 Convergent evolution misled taxonomy in schizothoracine fishes (Cypriniformes: Cyprinidae). Mol. Phylogenet. Evol. 134, 323-337. (doi:10.1016/j.ympev.2019.01.008)

50. Qi D, Chao Y, Guo S, Zhao L, Li T, Wei F, Zhao X. 2012 Convergent, parallel and correlated evolution of trophic morphologies in the subfamily schizothoracinae from the Qinghai-Tibetan Plateau. PLoS One 7, 1-10. (doi:10.1371/journal.pone.0034070)

51. Regmi B, Douglas M, Edds D, Douglas M. 2020 Geometric morphometric analyses define riverine and lacustrine species-flocks of Himalayan snowtrout (Cyprinidae: Schizothorax) in Nepal. Aquat. Biol. 30, 19-31. (doi:10.3354/ab00737)

738 52. Tshering S, Wangchuk K, Dorji S, Norbu P, Philipp DP, Claussen JE, Douglas ME, Douglas MR. 2017 Field Guide to Fishes of Western Bhutan. Thimphu, Bhutan: Kuensel $740 \quad$ Corporation, Ltd.

53. Terashima A. 1984 Three new species of the cyprinid genus Schizothorax from Lake Rara, northwestern Nepal. Japanese J. Ichthyol. 31, 122-135. (doi:10.11369/jji1950.31.122)

744 54. Dimmick WW, Edds DR. 2002 Evolutionary genetics of the endemic schizorathicine (Cypriniformes: Cyprinidae) fishes of Lake Rara, Nepal. Biochem. Syst. Ecol. 30, 919-

55. Qiao J, Hu J, Xia Q, Zhu R, Chen K, Zhao J, Yan Y, Chu L, He D. 2020 Pelagic-benthic 929. (doi:10.1016/S0305-1978(02)00030-3) resource polymorphism in Schizopygopsis thermalis Herzenstein 1891 (Pisces, Cyprinidae) in a headwater lake in the Salween River system on the Tibetan Plateau. Ecol. Evol. 10, 7431-7444. (doi:10.1002/ece3.6470)

56. Regmi B et al. 2020 The Himalayan uplift and the evolution of aquatic biodiversity across Asia $\square$ : Snowtrout (Cyprininae: Schizothorax) as a test case. bioRxiv (doi:10.1101/2020.10.12.336149)

754 57. Shrestha J. 1999 Coldwater fish and fisheries of Nepal. In Fish and fisheries at higher altitudes: Asia. FAO Fisheries Technical Paper No. 385 (ed T Petr), p. 304. Rome. 
58. Sehgal KL. 1999 Coldwater fish and fisheries in the Indian Himalayas: Rivers and streams. In Fish and fisheries at higher altitudes: Asia. FAO Fisheries Technical Paper No. 385 (ed T Petr), p. 304. Rome.

59. Petr T. 1999 Coldwater fish and fisheries in Bhutan. In Fish and fisheries at higher

60. Edds DR. 1993 Fish assemblage structure and environmental correlates in Nepal's Gandaki River. Copeia 1993, 48-60.

61. Changlu, Norbu S, Wangchuk K, Khanal GP, Tshering S, Tshering P. 2021 Diversity of

62. Li X, Guo B. 2020 Substantially adaptive potential in polyploid cyprinid fishes: Evidence from biogeographic, phylogenetic and genomic studies. Proc. R. Soc. B Biol. Sci. 287. (doi:10.1098/rspb.2019.3008)

63. Tong C, Tian F, Zhao K. 2017 Genomic signature of highland adaptation in fish: A case fishes across hydrological basins and elevational gradients in eastern Bhutan: A preliminary analysis. Bhutan J. Anim. Sci. 5, 27-36.

772

774

776

778

780

782

784

786

788

790

792

794 study in Tibetan Schizothoracinae species. BMC Genomics 18, 948. (doi:10.1186/s12864017-4352-8)

64. Favre A, Päckert M, Pauls SU, Jähnig SC, Uhl D, Michalak I, Muellner-Riehl AN. 2015 The role of the uplift of the Qinghai-Tibetan Plateau for the evolution of Tibetan biotas. Biol. Rev. Camb. Philos. Soc. 90, 236-253. (doi:10.1111/brv.12107)

65. Herbert TD, Lawrence KT, Tzanova A, Peterson LC, Caballero-Gill R, Kelly CS. 2016 Late Miocene global cooling and the rise of modern ecosystems. Nat. Geosci. 9, 843-847. (doi:10.1038/ngeo2813)

66. He D, Sui X, Sun H, Tao J, Ding C, Chen Y, Chen Y. 2020 Diversity, pattern and ecological drivers of freshwater fish in China and adjacent areas. Rev. Fish Biol. Fish. 30, 387-404. (doi:10.1007/s11160-020-09600-4)

67. Meirmans PG, Liu S, Van Tienderen PH. 2018 The analysis of polyploid genetic data. $J$. Hered. 109, 283-296. (doi:10.1093/jhered/esy006)

68. Dufresne F, Stift M, Vergilino R, Mable BK. 2014 Recent progress and challenges in population genetics of polyploid organisms: An overview of current state-of-the-art molecular and statistical tools. Mol. Ecol. 23, 40-69. (doi:10.1111/mec.12581)

69. Campbell MA, Hale MC, McKinney GJ, Nichols KM, Pearse DE. 2019 Long-term conservation of ohnologs through partial tetrasomy following whole-genome duplication in Salmonidae. G3 Genes, Genomes, Genet. 9, 2017-2028. (doi:10.1534/g3.119.400070)

70. Clark L V., Lipka AE, Sacks EJ. 2019 polyRAD: Genotype calling with uncertainty from sequencing data in polyploids and diploids. G3 Genes, Genomes, Genet. 9, 663-673. (doi:10.1534/g3.118.200913)

71. Clark L V., Mays W, Lipka AE, Sacks EJ. 2020 A population-level statistic for assessing Mendelian behavior of genotyping-by-sequencing data from highly duplicated genomes. bioRxiv (doi:10.1101/2020.01.11.902890)

72. Guo XZ, Zhang GR, Wei KJ, Yan RJ, Ji W, Yang R Bin, Wei QW, Gardner JPA. 2016 
Phylogeography and population genetics of Schizothorax o'connori: Strong subdivision in the Yarlung Tsangpo River inferred from mtDNA and microsatellite markers. Sci. Rep. 6, 1-15. (doi:10.1038/srep29821)

73. He D, Chen Y. 2009 Phylogeography of Schizothorax o'connori (Cyprinidae:

800 Schizothoracinae) in the Yarlung Tsangpo River, Tibet. Hydrobiologia 635, 251-262. (doi:10.1007/s10750-009-9918-2)

802 74. Peterson BK, Weber JN, Kay EH, Fisher HS, Hoekstra HE. 2012 Double digest RADseq: An inexpensive method for de novo SNP discovery and genotyping in model and nonmodel species. PLoS One 7, e37135.

75. Eaton DAR, Overcast I. 2020 ipyrad: Interactive assembly and analysis of RADseq datasets. Bioinformatics 36, 2592-2594.

76. Zhou C et al. 2020 Comprehensive transcriptome data for endemic Schizothoracinae fish

77. Li H, Ruan J, Durbin R. 2008 Mapping short DNA sequencing reads and calling variants in the Tibetan Plateau. Sci. Data 7, 1-7. (doi:10.1038/s41597-020-0361-6)

78. Li H, Durbin R. 2009 Fast and accurate short read alignment with Burrows-Wheeler

79. Weiß CL, Pais M, Cano LM, Kamoun S, Burbano HA. 2018 nQuire: a statistical 816 80. Adams DC, Otárola-Castillo E. 2013 Geomorph: An r package for the collection and
analysis of geometric morphometric shape data. Methods Ecol. Evol. 4, 393-399. $818 \quad$ (doi:10.1111/2041-210X.12035)

81. Venables WN, Ripley BDB. 2002 Modern Applied Statistics with S. Fourth. New York: framework for ploidy estimation using next generation sequencing. BMC Bioinformatics 19, 122. (doi:10.1186/s12859-018-2128-z)

82. Smith ML, Hahn MW. 2021 New approaches for inferring phylogenies in the presence of Springer.

83. Sarmashghi S, Bohmann K, Thomas P Gilbert M, Bafna V, Mirarab S. 2019 Skmer: paralogs. Trends Genet. 37, 174-187. (doi:10.1016/j.tig.2020.08.012) Biol. 20, 34. (doi:10.1101/230409)

826 84. Balaban M, Sarmashghi S, Mirarab S. 2020 APPLES: Scalable distance-based phylogenetic placement with or without alignments. Syst. Biol. 69, 566-578.

828 (doi:10.1093/sysbio/syz063)

85. Lefort V, Desper R, Gascuel O. 2015 FastME 2.0: A comprehensive, accurate, and fast distance-based phylogeny inference program. Mol. Biol. Evol. 32, 2798-2800. (doi:10.1093/molbev/msv150)

832 86. Nguyen L-TL-T, Schmidt HA, von Haeseler A, Minh BQ. 2014 IQ-TREE: A fast and effective stochastic algorithm for estimating Maximum-Likelihood phylogenies. Mol. Biol. Evol. 32, 268-274. (doi:10.1093/molbev/msu300)

87. De Maio N, Schrempf D, Kosiol C. 2015 PoMo: An allele frequency-based approach for 
species tree estimation. Syst. Biol. 64, 1018-1031. (doi:10.1093/sysbio/syv048)

88. Pritchard JK, Stephens M, Donnelly P. 2000 Inference of population structure using multilocus genotype data. Genetics 155, 945-959. (doi:10.1111/j.14718286.2007.01758.X)

840 89. Stift M, Kolář F, Meirmans PG. 2019 Structure is more robust than other clustering methods in simulated mixed-ploidy populations. Heredity 123, 429-441.

$842 \quad$ (doi:10.1038/s41437-019-0247-6)

844

90. Kopelman NM, Mayzel J, Jakobsson M, Rosenberg NA, Mayrose I. 2015 Clumpak: a

844
program for identifying clustering modes and packaging population structure inferences across K. Mol. Ecol. Resour. 15, 1179-1191.

846 91. Evanno G, Regnaut S, Goudet J. 2005 Detecting the number of clusters of individuals using the software STRUCTURE: A simulation study. Mol. Ecol. 14, 2611-2620.

$848 \quad$ (doi:10.1111/j.1365-294X.2005.02553.x)

850

852

854

856

858 92. Martin BT, Chafin TK, Douglas MR, Placyk Jr. JS, Birkhead RD, Phillips CA, Douglas
ME. 2021 The choices we make and the impacts we have: Machine learning and species delimitation in North American box turtles (Terrapene spp.). Mol. Ecol. Resour. Early View.

93. Jombart T. 2008 Adegenet: A R package for the multivariate analysis of genetic markers. Bioinformatics 24, 1403-1405. (doi:10.1093/bioinformatics/btn129)

94. Jombart T, Devillard SS, Balloux FF. 2010 Discriminant analysis of principal components: a new method for the analysis of genetically structured populations. BMC Genet. 11, 94. (doi:doi: 10.1186/1471-2156-11-94)

95. Pickrell JK, Pritchard JK. 2012 Inference of population splits and mixtures from genomewide allele frequency data. PLoS Genet. 8, e1002967. (doi:10.1371/journal.pgen.1002967)

$86096 . \quad$ Fitak RR. 2019 optM: an R package to optimize the number of migration edges using threshold models. https://CRAN.R-project.org/package $=$ dplyr

862 97. Malinsky M, Matschiner M, Svardal H. 2021 Dsuite - Fast D-statistics and related admixture evidence from VCF files. Mol. Ecol. Resour. 21, 584-595. (doi:10.1111/1755-

$864 \quad 0998.13265)$

866

98. Patterson N, Moorjani P, Luo Y, Mallick S, Rohland N, Zhan Y, Genschoreck T, Webster T, Reich D. 2012 Ancient admixture in human history. Genetics 192, 1065-1093. (doi:10.1534/genetics.112.145037)

868 99. Oaks JR. 2019 Full Bayesian comparative phylogeography from genomic data. Syst. Biol. 68, 371-395. (doi:10.1093/sysbio/syy063)

870 100. Oaks JR, L'Bahy N, Cobb KA. 2020 Insights from a general, full-likelihood Bayesian approach to inferring shared evolutionary events from genomic data: Inferring shared 872 demographic events is challenging*. Evolution 74, 2184-2206. (doi:10.1111/evo.14052)

101. Chafin TK, Douglas MR, Bangs MR, Martin BT, Mussmann SM, Douglas ME. 2021 Taxonomic uncertainty and the anomaly zone: Phylogenomics disentangle a rapid radiation to resolve contentious species (Gila robusta complex) in the Colorado River. 
Genome Biol. Evol. , In press. (doi:10.1101/692509)

102. Luu K, Bazin E, Blum MGB. 2017 pcadapt: an R package to perform genome scans for selection based on principal component analysis. Mol. Ecol. Resour. 17, 67-77. (doi:10.1111/1755-0998.12592)

880 103. Conesa A, Götz S, García-Gómez JM, Terol J, Talón M, Robles M. 2005 Blast2GO: A universal tool for annotation, visualization and analysis in functional genomics research. Bioinformatics 21, 3674-3676. (doi:10.1093/bioinformatics/bti610)

104. Hunter S et al. 2009 InterPro: The integrative protein signature database. Nucleic Acids Res. 37, 211-215. (doi:10.1093/nar/gkn785)

105. Boeckmann B et al. 2003 The SWISS-PROT protein knowledgebase and its supplement TrEMBL in 2003. Nucleic Acids Res. 31, 365-370. (doi:10.1093/nar/gkg095)

106. Sayols S. 2020 rrvgo: a Bioconductor package to reduce and visualize Gene Ontology terms. https://ssayols.github.io/rrvgo.

107. Nei M. 1987 Molecular evolutionary genetics. Columbia university press.

890 108. Jost L. 2008 GST and its relatives do not measure differentiation. Mol. Ecol. 17, 40154026. (doi:10.1111/j.1365-294X.2008.03887.x)

892 109. Smith J, Kronforst MR. 2013 Do Heliconius butterfly species exchange mimicry alleles? Biol. Lett. 9, 20130503. (doi:10.1098/rsbl.2013.0503)

894 110. Xiao S et al. 2020 Genome of tetraploid fish Schizothorax o'connori provides insights into early re-diploidization and high-altitude adaptation. iScience 23, 101497.

$896 \quad$ (doi:10.1016/j.isci.2020.101497)

111. Novikova PY et al. 2020 Polyploidy breaks speciation barriers in Australian burrowing frogs Neobatrachus. PLoS Genet. 16, 1-24. (doi:10.1371/journal.pgen.1008769)

112. Povilus RA, Diggle PK, Friedman WE. 2018 Evidence for parent-of-origin effects and 900 interparental conflict in seeds of an ancient flowering plant lineage. Proc. R. Soc. B Biol. Sci. 285, 20172491. (doi:10.1098/rspb.2017.2491)

902 113. Lafon-Placette C et al. 2017 Endosperm-based hybridization barriers explain the pattern of gene flow between Arabidopsis lyrata and Arabidopsis arenosa in Central Europe. Proc. Natl. Acad. Sci. U. S. A. 114, E1027-E1035. (doi:10.1073/pnas.1615123114)

114. Schmickl R, Yant L. 2021 Adaptive introgression: how polyploidy reshapes gene flow

115. Marburger S et al. 2019 Interspecific introgression mediates adaptation to whole genome duplication. Nat. Commun. 10, 1-11. (doi:10.1038/s41467-019-13159-5)

116. Pecinka A, Fang W, Rehmsmeier M, Levy AA, Mittelsten Scheid O. 2011

$910 \quad$ Polyploidization increases meiotic recombination frequency in Arabidopsis. BMC Biol. 9, 24. (doi:10.1186/1741-7007-10-33)

912 117. Monnahan P et al. 2019 Pervasive population genomic consequences of genome duplication in Arabidopsis arenosa. Nat. Ecol. Evol. 3, 457-468. (doi:10.1038/s41559-

914 019-0807-4) 
118. Otto SP. 2007 The evolutionary consequences of polyploidy. Cell 131, 452-462.

(doi:10.1016/j.cell.2007.10.022)

119. Baniaga AE, Marx HE, Arrigo N, Barker MS. 2020 Polyploid plants have faster rates of multivariate niche differentiation than their diploid relatives. Ecol. Lett. 23, 68-78. (doi:10.1111/ele.13402)

920 120. Van De Peer Y, Mizrachi E, Marchal K. 2017 The evolutionary significance of polyploidy. Nat. Rev. Genet. 18, 411-424. (doi:10.1038/nrg.2017.26)

922 121. Bangs MR, Douglas MR, Chafin TK, Douglas ME. 2020 Gene flow and species delimitation in fishes of Western North America: Flannelmouth (Catostomus latipinnis) and Bluehead sucker (C. Pantosteus discobolus). Ecol. Evol. 10, 6477-6493.

122. Chafin TK, Douglas MR, Martin BT, Douglas ME. 2019 Hybridization drives genetic erosion in sympatric desert fishes of western North America. Heredity 123, 759-773.

123. Bangs MR, Douglas MR, Brunner PC, Douglas ME. 2020 Reticulate evolution as a management challenge: Patterns of admixture with phylogenetic distance in endemic fishes of western North America. Evol. Appl. 13, 1400-1419. (doi:10.1111/eva.13042)

930 124. Sharma A, Dubey VK, Johnson JA, Rawal YK, Sivakumar K. 2021 Is there always space at the top? Ensemble modeling reveals climate-driven high-altitude squeeze for the vulnerable snow trout Schizothorax richardsonii in Himalaya. Ecol. Indic. 120, 106900. (doi:10.1016/j.ecolind.2020.106900)

934 125. Todesco M et al. 2016 Hybridization and extinction. Evol. Appl. 9, 892-908. (doi:10.1111/eva.12367)

936 126. Seehausen O, Takimoto G, Roy D, Jokela J. 2008 Speciation reversal and biodiversity dynamics with hybridization in changing environments. Mol. Ecol. 17, 30-44.

938 (doi:10.1111/j.1365-294X.2007.03529.x)

127. Mohan M. 2005 Spawning biology of snow trout, Schizothorax richardsonii (Gray) from River Gaula (Kumaon, Himalaya). Indian J. Fish. 52, 451-457.

128. Bangs MR, Douglas MR, Thompson P, Douglas ME. 2017 Anthropogenic Impacts Facilitate Native Fish Hybridization in the Bonneville Basin of Western North America. Trans. Am. Fish. Soc. 146, 16-21. (doi:10.1080/00028487.2016.1235611)

944 129. Dibble KL, Yackulic CB, Schmidt JC, Kennedy TA, Bestgen KR. 2020 Water storage decisions will determine the distribution and persistence of imperiled river fishes. Ecol.

$946 \quad$ Appl. (doi:10.1002/eap.2279)

130. Douglas MR, Douglas ME. 2000 Late season reproduction by big-river Catostomidae in Grand Canyon (Arizona). Copeia 2000, 238-244. (doi:10.1643/00458511(2000)2000[0238:LSRBBR]2.0.CO;2)

950 131. Ogino K, Dash SK, Nakayama M. 2019 Change to hydropower development in Bhutan and Nepal. Energy Sustain. Dev. 50, 1-17. (doi:10.1016/j.esd.2019.02.005)

952 132. Dorji T, Linke S, Sheldon F. 2020 Freshwater conservation planning in the context of nature needs half and protected area dynamism in Bhutan. Biol. Conserv. 251, 108785.

954 133. Foll M, Gaggiotti OE, Daub JT, Vatsiou A, Excoffier L. 2014 Widespread signals of 
convergent adaptation to high altitude in Asia and America. Am. J. Hum. Genet. 95, 394407. (doi:10.1016/j.ajhg.2014.09.002)

134. Witt KE, Huerta-Sánchez E. 2019 Convergent evolution in human and domesticate adaptation to high-altitude environments. Philos. Trans. R. Soc. B Biol. Sci. 374. (doi:10.1098/rstb.2018.0235)

960 135. Chi W, Ma X, Niu J, Zou M. 2017 Genome-wide identification of genes probably relevant to the adaptation of schizothoracins (Teleostei: Cypriniformes) to the uplift of the

962 Qinghai-Tibet Plateau. BMC Genomics 18, 1-8. (doi:10.1186/s12864-017-3703-9)

964

136. Menon AGK. 1949 Notes on fishes in the Indian Museum. XLIV. Fishes from the Kosi Kimalayas, Nepal. Rec. Indian Museum 47, 231-237.

137. Jacobsen D. 2008 Low oxygen pressure as a driving factor for the altitudinal decline in taxon richness of stream macroinvertebrates. Oecologia 154, 795-807.

966 taxon richness of stream macroinver

968 138. Hoppeler F, Tachamo Shah RD, Shah DN, Jähnig SC, Tonkin JD, Sharma S, Pauls SU. 2016 Environmental and spatial characterisation of an unknown fauna using DNA sequencing - an example with Himalayan Hydropsychidae (Insecta: Trichoptera). Freshw. Biol. 61, 1905-1920. (doi:10.1111/fwb.12824)

972 139. Tonkin JD, Tachamo Shah RD, Shah DN, Hoppeler F, Jahnig SC, Pauls SU. 2017 Metacommunity structuring in Himalayan streams over large elevational gradients: the role of dispersal routes and niche characteristics. J. Biogeogr. 44, 62-74. (doi:10.1111/jbi.12895)

976 140. Li J, He Q, Hua X, Zhou J, Xu H, Chen J, Fu C. 2009 Climate and history explain the species richness peak at mid-elevation for Schizothorax fishes (Cypriniformes:

978 Cyprinidae) distributed in the Tibetan Plateau and its adjacent regions. Glob. Ecol. Biogeogr. 18, 264-272. (doi:10.1111/j.1466-8238.2008.00430.x) 


\section{Tables and Figures}

Figure 1: Pattern and process in the formation of apparent ecotypes. Ecotypy is often inferred via a juxtaposition of discordant spatial, phylogenetic, and phenotypic patterns (left; differentially adapted forms represented in gold and purple). Evolutionary scenarios (right) which can generate these patterns include (A) Parallel selection upon standing variation; (B) Recurrent de novo adaptation via independent mutation; (C) Hybridization among co-occuring ecophenotypes following a common origin; or (D) The singular origin of an adaptive mutation, which is then spread via adaptive introgression.

990
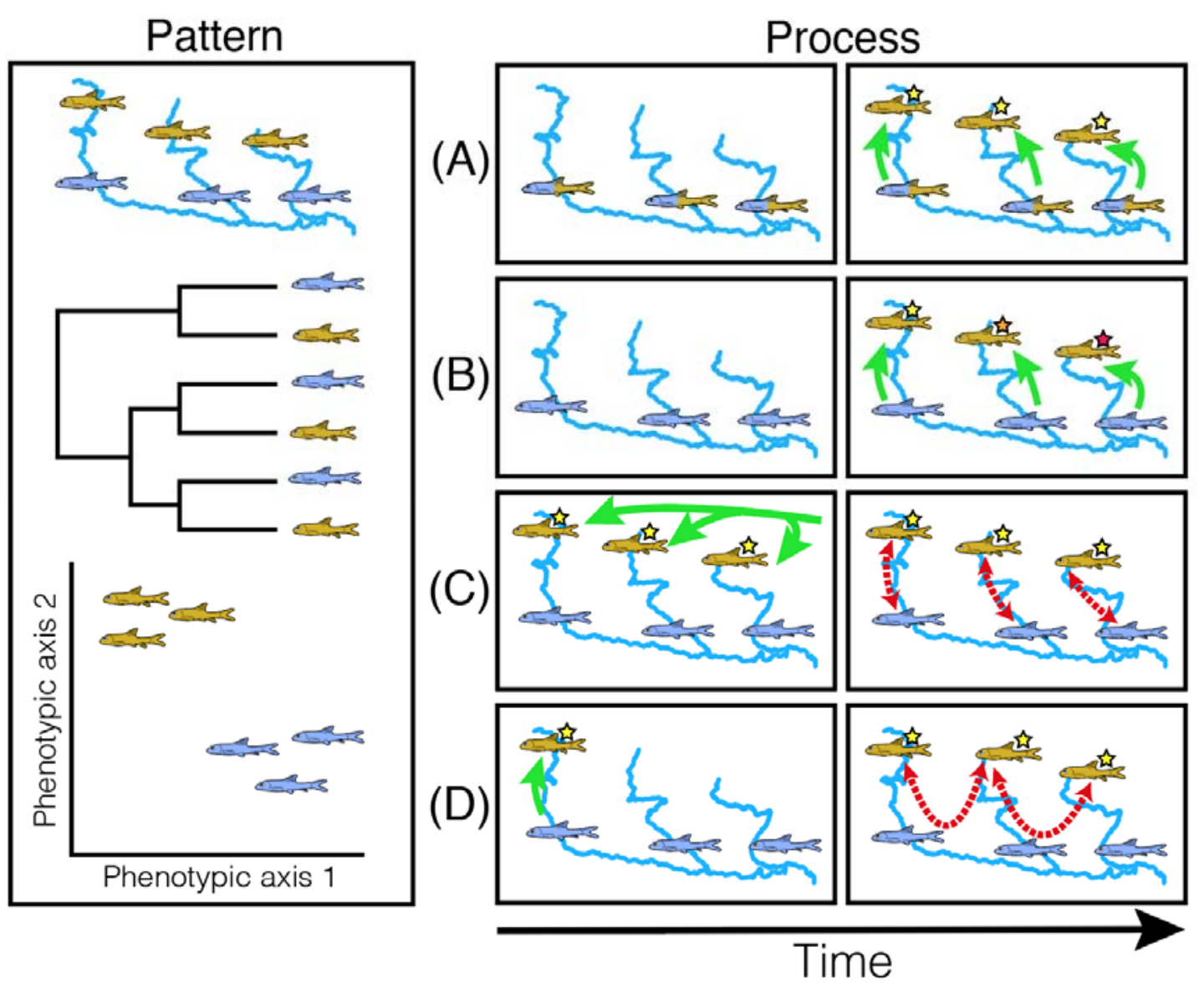
994 Figure 2: Sampling locality information for N=96 Schizothorax spp. selected for ddRAD sequencing. Sites represent major Himalayan tributaries of the Brahmaputra and Ganges rivers from Nepal and Bhutan (A). Samples for five species ( $S$.

996 macrophthalmus, S. nepalensis, S. progastus, S. raraensis, and S. richardsonii) were collected from 11 sites in the major drainages of Nepal (Karnali, Gandaki, and Koshi; B). Major drainages of Bhutan (Wang Chhu, Punatsang Chhu, and Mangde Chhu) were

998 represented by two species (S. progastus and S. cf. oconnori) collected from 11 localities (C). Schizothorax progastus from both Nepal (D) and Bhutan (E) were collected from relatively lower elevations ( 600-1200m), whereas S. richardsonii (Nepal; D) and S. $c f$.

1000 oconnori (Bhutan; E) were generally found $>1200 \mathrm{~m}$.
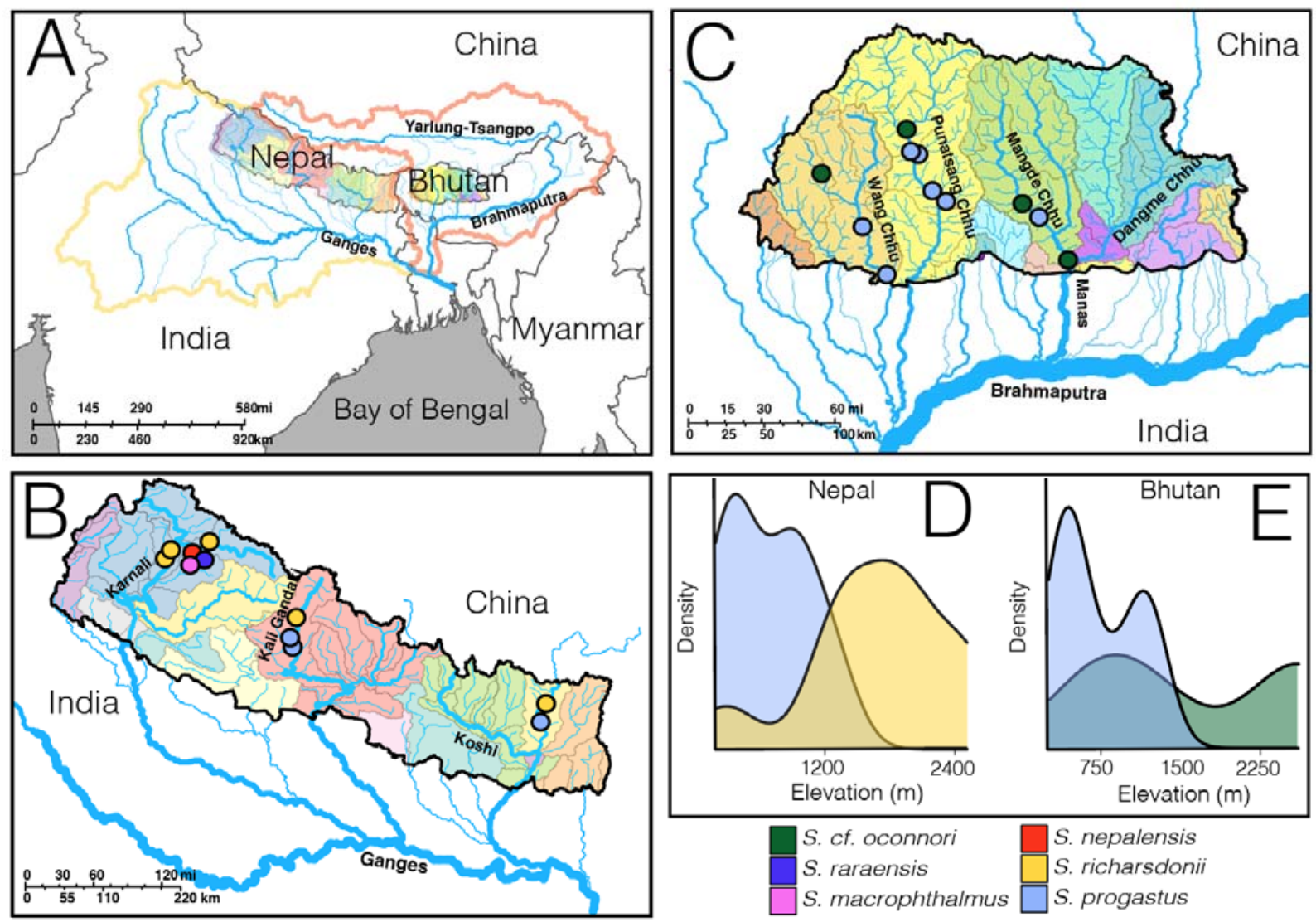
Figure 3: Evaluation of ploidy from $N=48,350$ ddRAD loci for six Schizothorax species. (Left) Distributions of base frequencies among raw reads representing bi-allelic SNPs for six Schizothorax spp. collected from Nepal [S. macrophthalmus, S. nepalensis, S.

1004 progastus (solid line), S. raraensis, and S. richardsonii] and Bhutan [S. cf. oconnori and S. progastus (dashed line)]. (Right)

Likelihoods from Gaussian Mixture Models of fixed ploidy (e.g., diploid, triploid, tetraploid), divided by the likelihood under a model of freely variable base frequencies ( $\left.=\log L_{\text {Ploidy }} / \log L_{\text {Free }}\right)$.
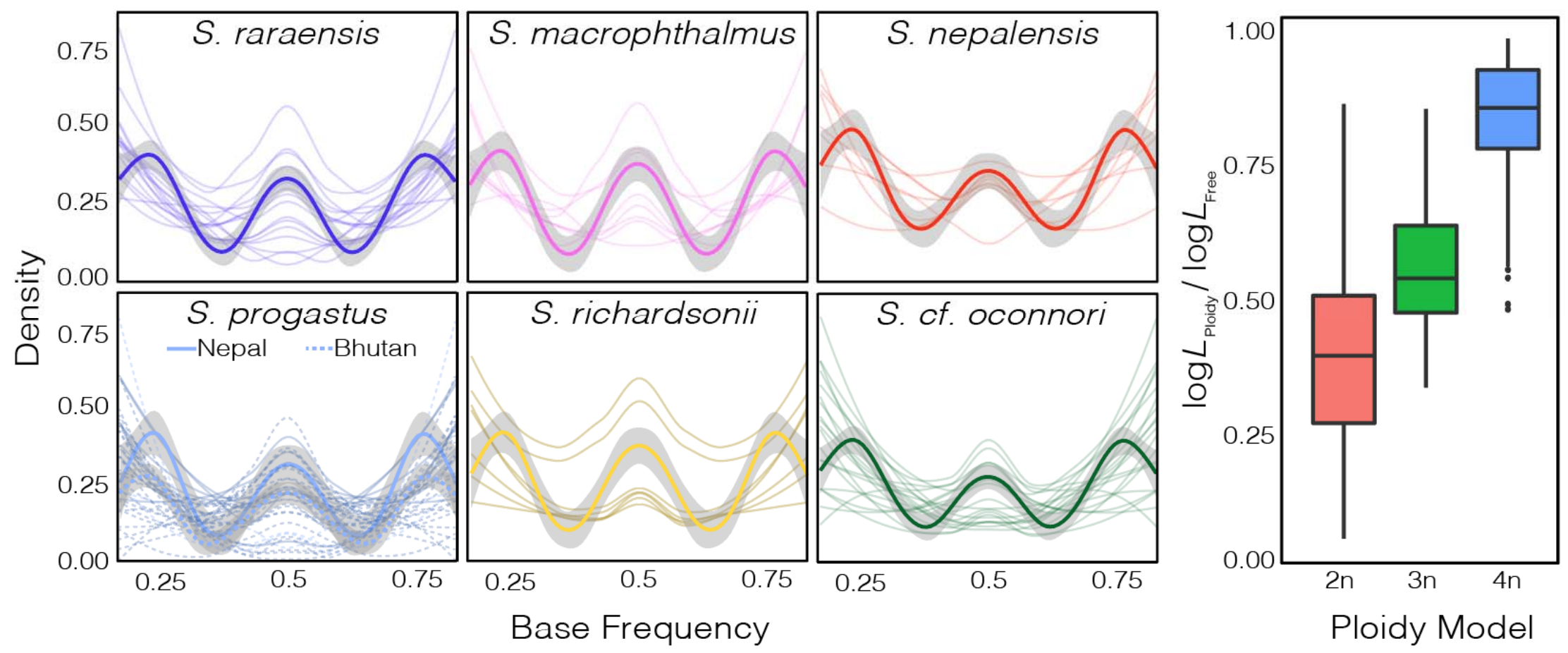
1008 Figure 4: Discriminant analysis of principal components (DAPC) of morphological shape variation among five Schizothorax species. Results represent $N=528$ individuals of $S$.

1010 macrophthalmus, S. nepalensis, S. progastus, S. raraensis, and S. richardsonii collected from the Gandaki, Karnali (to include Lake Rara), and Koshi drainages of Nepal, and Procrustes-aligned

1012 two-dimensional Cartesian coordinates for 18 anatomical landmarks.

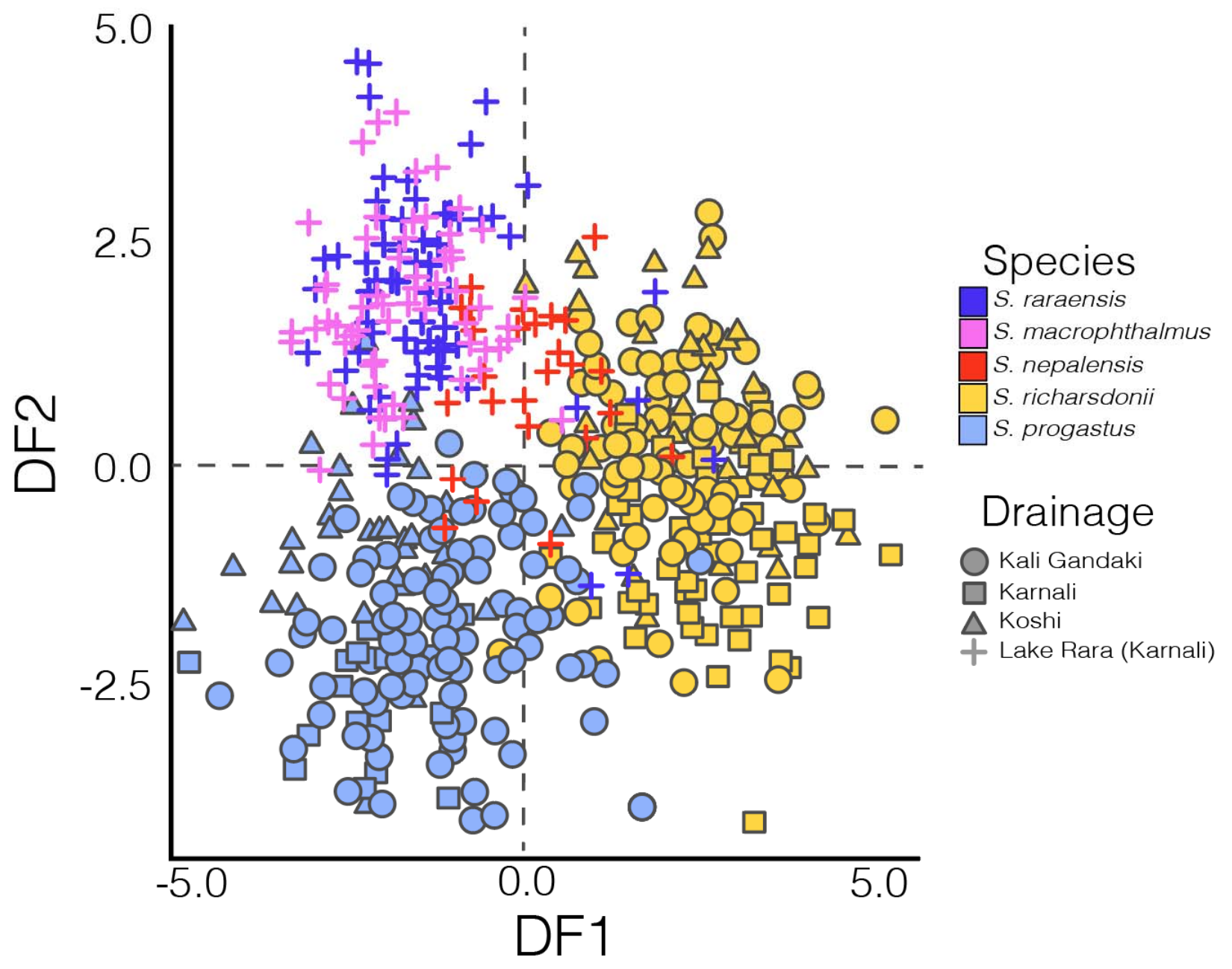


Figure 5: Visualization of genetic variation among six Schizothorax species, as assessed across $N=15,547$ statistically diploid SNPs. Visualizations represent the first two discriminant functions from a discriminant analysis of principal components (DAPC) computed across (A) all samples from Bhutan (S. cf. oconnori and S. progastus) and Nepal (S. macrophthalmus, S. nepalensis, S. progastus, S. raraensis, and $S$. richardsonii); (B) Only those samples from Bhutan, additionally partitioned by major drainage encompassing the samples locality (i.e., Wang Chhu, Mangde Chhu, or Punatsang Chhu); and (C) Only individuals samples in Nepal. Nepali samples are partitioned by major drainage (i.e., Gandaki, Koshi, and Karnali), with species from Lake Rara (S. macrophthalmus, S. nepalensis, and S. raraensis) additionally separated.

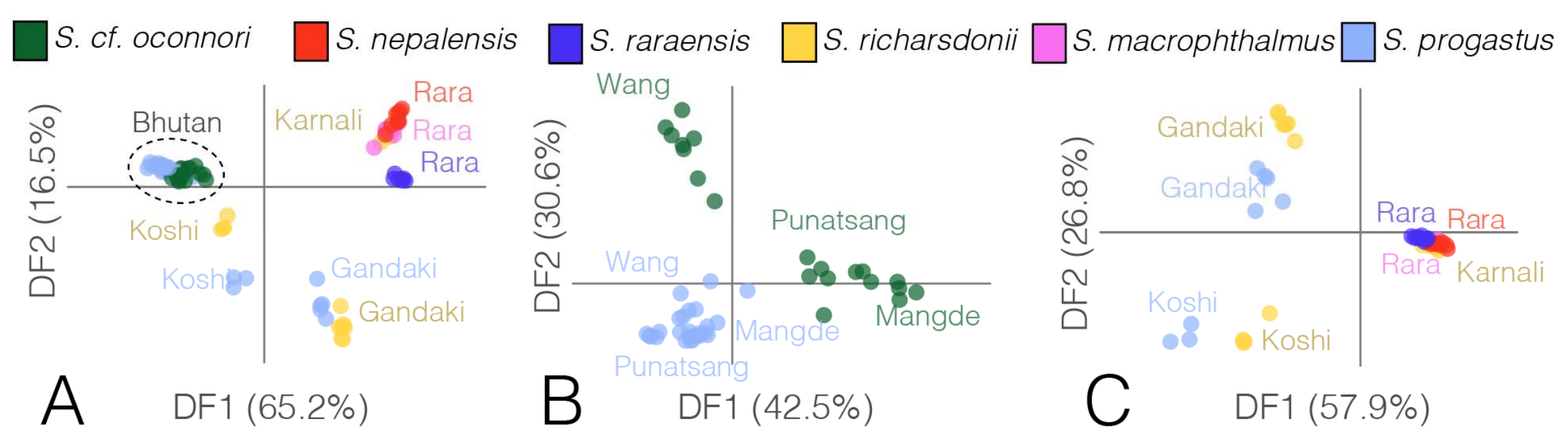


1024 Figure 6: Phylogenetic and population structure of $N=93$ Schizothorax spp. collected in major drainages of Bhutan and Nepal. Results represent (A) an unrooted alignment/assembly free

1026 phylogeny inferred from k-mer distances, computed from raw ddRAD reads. Clades are grouped by drainage, and with colored bars denoting tips grouped by taxon ( $S$. macrophthalmus, $S$.

1028 nepalensis, $S$. cf. oconnori, S. progastus, S. raraensis, and S. richardsonii). (B) Bar plots are provided for population assignments at $K=3$ and $K=7$ for (left) 10,884 transcriptome-aligned

1030 SNPs and (right) 35,319 de novo assembled SNPs. (C) TREEMIX analyses of population mixtures, with colored arrows representing inferred migration weights.

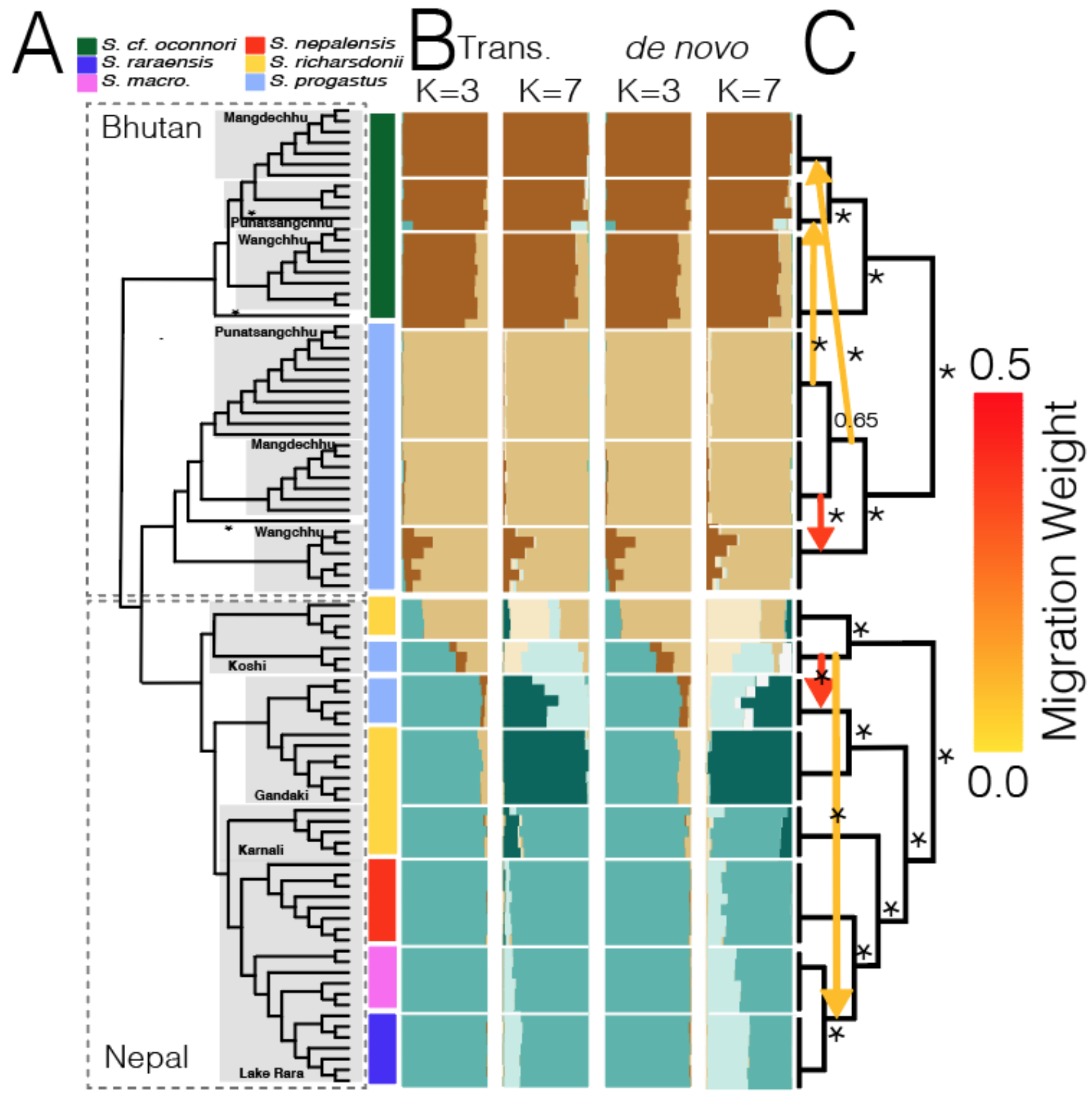


Figure 7: Population tree generated for $N=93$ Schizothorax spp. divided into 13 populations 1034 using a polymorphism-aware model applied to 15,543 ddRAD SNPs. Nodal values represent bootstrap support expressed as percentage of 1,000 ultra-fast bootstraps.

1036

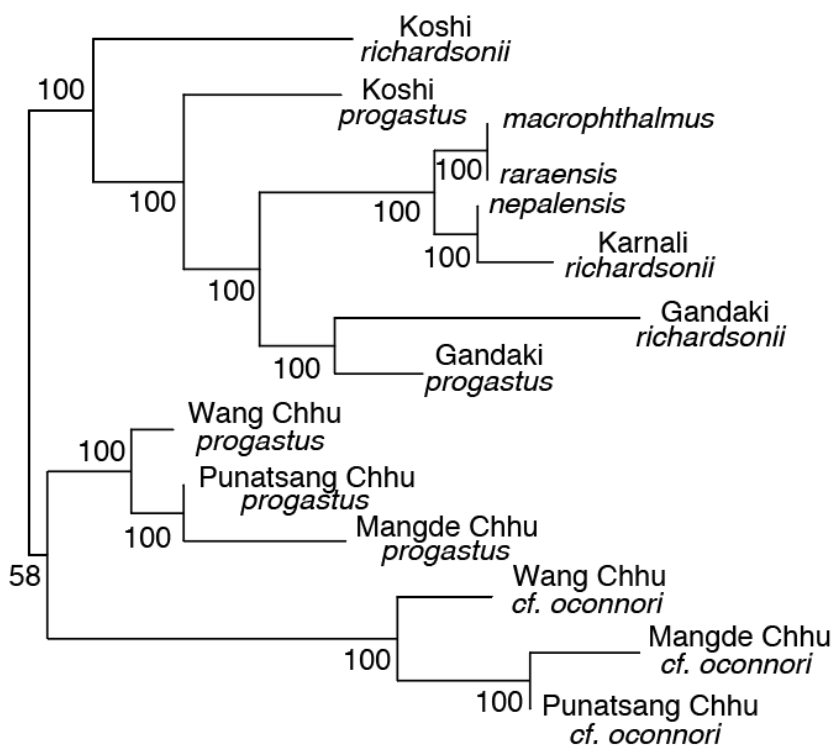


Figure 8: Tests of co-divergence among lineage pairs in Nepal and Bhutan. (A) and (C) show posterior probability distributions on divergence times for Nepal and Bhutan, respectively. Nepalese results (A) represent divergence of Schizothorax richardsonii (=rich.) and $S$. progastus (=prog.) in the Gandaki and Koshi rivers, $S$. richardsonii from the Karnali River with the 'Lake Rara' complex, $S$. macrophthalmus (=macrop.) with $S$. raraensis (=rara.) and $S$. nepalensis (=nepal.). Results for Bhutan depict $S$. cf. oconnori (=ocon.) and S. progastus from the Punatsang Chhu (=Puna.), Mangde Chhu, and Wang Chhu rivers. (B) and (D) depict posterior (dark bars) and prior (light bars) probabilities of the numbers of co-divergences.

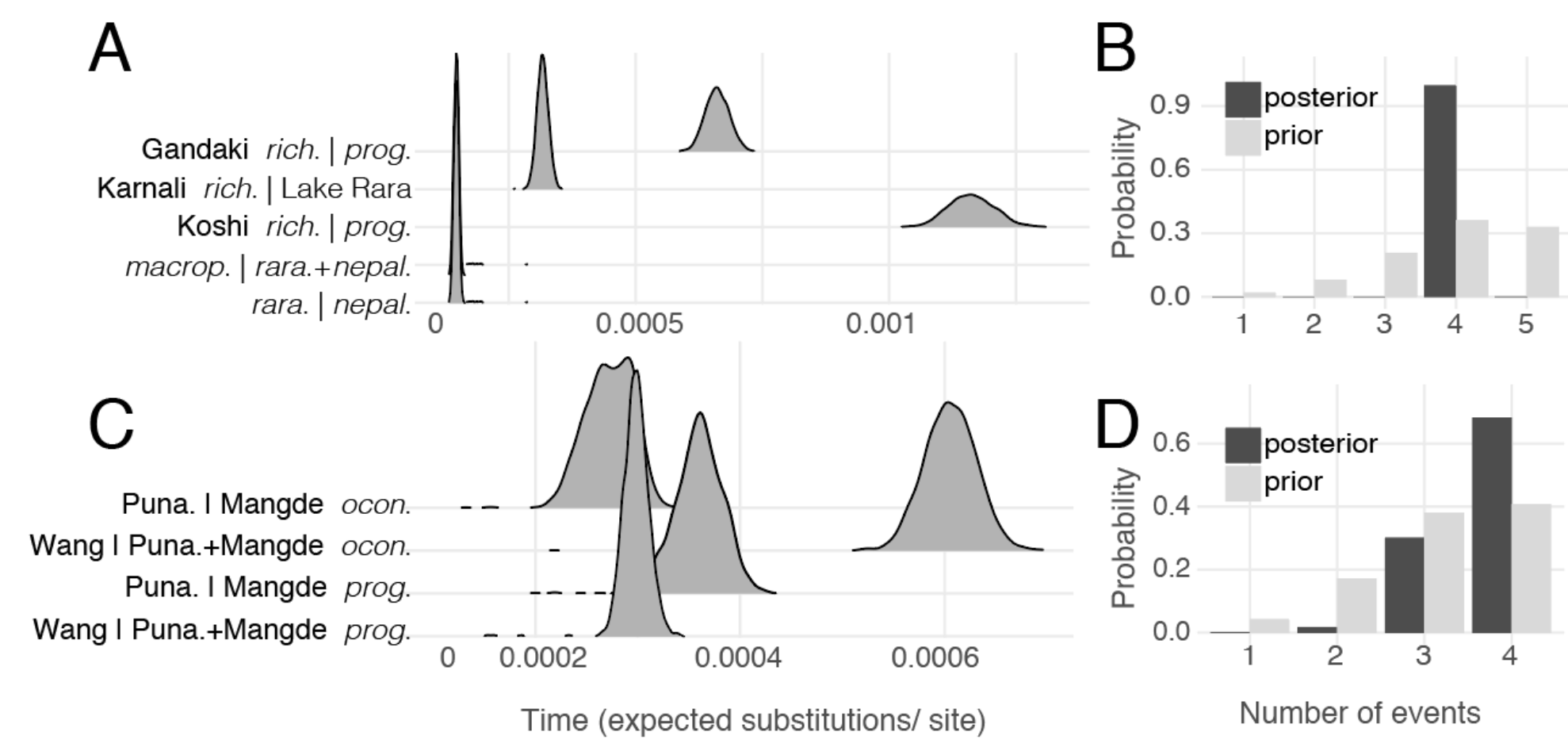


Figure 9: TREEMIX analyses of population mixtures among S. progastus and S. richardsonii pairs collected from the Gandaki and Koshi rivers of Nepal, based on partitioning different subsets of loci. (A) Loci were grouped by ratios of $D_{\mathrm{XY}}$ (computed between

1052 heterospecifics within each drainage) and $D_{\text {Xo }}$ (computed between conspecific $S$. richardsonii), with those loci having a $D_{\mathrm{XY}}$ ratio $>$ 1.0 in both Gandaki and Koshi comparisons (i.e., greater distances among S. richardsonii and S. progastus within drainage than $S$.

1054 richardsonii among drainages) analyzed separately. (B) Loci were also partitioned into four bins defined by per-locus $F_{\mathrm{ST}}$ computed in Gandaki (above; red) and Koshi (below; blue) pairs. Colored arrows indicate inferred migrations within each partitioned analysis, with the color indicating the migration weight.
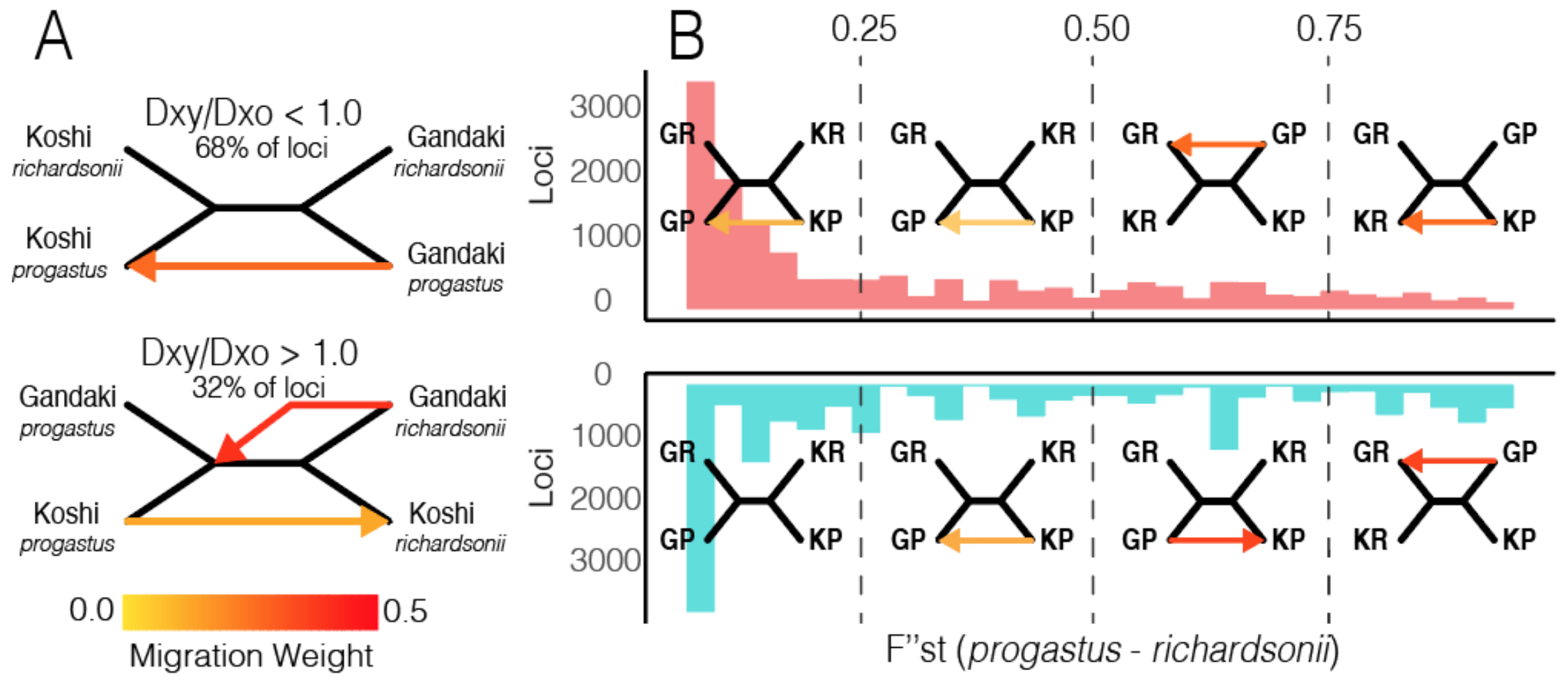
bioRxiv preprint doi: https://doi.org/10.1101/2021.04.16.440204; this version posted September 2, 2021. The copyright holder for this preprint (which was not certified by peer review) is the author/funder, who has granted bioRxiv a license to display the preprint in perpetuity. It is made available under aCC-BY-NC-ND 4.0 International license.

\section{8}

